\title{
A Ship Domain-Based Method of Determining Action Distances for Evasive Manoeuvres in Stand-On Situations
}

\author{
Rafal Szlapczynski ${ }^{(D)}{ }^{1}$ Przemyslaw Krata, ${ }^{2}$ and Joanna Szlapczynska ${ }^{(D)}{ }^{2}$ \\ ${ }^{1}$ Faculty of Ocean Engineering and Ship Technology, Gdansk University of Technology, Poland \\ ${ }^{2}$ Faculty of Navigation, Gdynia Maritime University, Poland \\ Correspondence should be addressed to Joanna Szlapczynska; asiasz@am.gdynia.pl
}

Received 10 March 2018; Revised 27 June 2018; Accepted 18 July 2018; Published 10 October 2018

Academic Editor: Monica Menendez

Copyright (C) 2018 Rafal Szlapczynski et al. This is an open access article distributed under the Creative Commons Attribution License, which permits unrestricted use, distribution, and reproduction in any medium, provided the original work is properly cited.

\begin{abstract}
A ship encounter can be considered safe if neither of ships' domains (defined areas around ships) is intruded by other ships. Published research on this includes optimising collision avoidance manoeuvres fulfilling domain-based safety conditions. However, until recently there was no method, using ship's domain to determine exact moment when a particular collision avoidance manoeuvre can still be successfully performed. The authors have already proposed such method for give-way encounters. In the paper, documenting continuation of the research, another kind of scenarios is considered. This paper is focused on situations where the own ship is the stand-on one and the target is supposed to manoeuvre. The presented method uses a ship's dynamics model to compute distance necessary for a manoeuvre successful in terms of avoiding domain violations. Additionally, stability-related phenomena and their impact on possible manoeuvres in heavy weather are taken into account. The method and applied models are illustrated in a series of simulation results. The simulations cover various examples of stand-on situations, including encounters in heavy weather conditions. Discussed manoeuvres may be limited to course alteration or may combine turns with speed reduction.
\end{abstract}

\section{Introduction}

Safety of ship, cargo, and crew has always been a key priority in worldwide maritime transportation. Distance between ships has always been the most important factor contributing to the level of safety in congested harbour entrances and confined and high-density open waters. Thus, a minimal but safe two-dimensional space distance between ships formed the basis for a ship safety domain defined over 40 years ago by Fujii and Tanaka [1]. It was followed by similar but differing in shape definitions [2,3], all considered nowadays as classical. They define a two-dimensional area around a ship that cannot be intruded by any other ship or obstacle. Shape of this area is either round, possibly with few sectors for different radii as in [2], or elliptic [3]. The 2D definitions have been further extended to a three-dimensional safety space domain, comprising also of vertical air draft and safe under-keel clearance $[4,5]$. The 3D domain approach is surprisingly seldom, if ever, utilized in ship collision avoidance research.
Recent development of 2D ship domains is in most cases related to collision avoidance [6-10]. This domain application type has been evidenced by numerous works, including [11, 12]. But it must be mentioned that there is a number of other successful applications of ship domains, namely,

(i) analysis of waterway capacity [13],

(ii) AIS-based detection of near-misses [14-17],

(iii) analysis of waterway collision risk [18-21].

As for ship's manoeuvrability, it has also been well researched. Lately, simulation and computer technology have reached a level of maturity that allows researchers to integrate ship dynamics into collision avoidance in a sophisticated manner. Such approaches include Fast-Time Simulation method $[22,23]$, which uses full 3-DoF and 6DoF models to determine time and distance necessary for evasive manoeuvres. However, until recently, there had been no method, which would apply ship's domain to this problem. Therefore, the current paper uses both ship's domain and 
ship's manoeuvrability models in order to determine the last moment when a particular collision avoidance manoeuvre still could be successfully performed. The method presented here was inspired by action area [24] and critical distance first described in [25] and further developed in [26]. This paper presents the method applied to solving the own ship standon scenarios resulting in displaying so-called action lines of distances, i.e., boundary lines defining ship's arena.

Last but not least, it ought to be underlined that the method presented here remains in line with goals and actions taken by International Maritime Organization (IMO) towards increasing safety of navigation and minimizing maritime risks [19, 27-29]. One among many such actions was adopting Formal Safety Assessment (FSA) to maritime industry by IMO in 2002 [30-32]. FSA is a methodology of enhancing safety via risk assessment and its evaluation and comprises five elements, namely,

(1) identification of hazards (when dangerous scenarios, their potential causes, and outcomes are listed),

(2) assessment of risks (when risk factors are evaluated),

(3) risk control options (when measures to control and reduce the risks are proposed),

(4) cost benefit assessment (when cost effectiveness of each risk control option is being determined),

(5) recommendations for decision-making (when information collected during points (1)-(4), given above, is gathered and provided to the user).

FSA applied to ship collision avoidance can be supported by the proposed method nearly throughout the entire process. For given encounter situation, motion parameters of the engaged ships, and assumed ship domain the action line determined by the method provides information of collision risk with particular targets and facilitates planning a manoeuvre to avoid domain violation, by far less potentially disastrous than a collision. Moreover, the method expedites cost benefit assessment since additional elements, typical for stand-on situations, are taken into account, namely, the model of ship's dynamics and stability-related constraints. Finally, the method presents its results in a graphical manner, which makes the communication with user easier and final decision-making straightforward. Obviously, application of FSA by IMO is evolving [33] and probably still will be, especially in upcoming era of autonomous shipping. Thus, the presented approach would be developed to stay in accordance with amendments of the technological, legal, and organizational aspects of maritime transportation.

Focusing back on the up-to-date version of the method determining action distances in stand-on situations, the rest of the paper is organized as follows. First literature review is presented in Section 2. The method of manoeuvre's last moment determination is outlined in Section 3, including also a description of its key algorithm. The applied model of ship dynamics' is provided in Section 4. Results obtained for an example ship are provided by Section 5 . They are then discussed in Section 6. Finally, the summary and conclusions are presented in Section 7.

\section{Literature Review}

In a typical collision avoidance approach it is assumed to have enough time for optimisation; thus the approach is focused on manoeuvres done in advance ([34], Tam et al., 2009; Tsou et al., 2010; [35], Praczyk, 2015; Zhang et al., 2015; Tsou, 2016; Pietrzykowski et al., 2017). However, there are only few papers researching at which exact moment the manoeuvre ought to be initiated in order to achieve safe separation between the ships. This thread of research has been initiated by a concept of an evasion area (named arena) around a ship $[36,37]$. Following that close quarters have been defined in [38], where the author observed that COLREGS $[39,40]$ do not precisely instruct navigators on specific distances in which the evasive action is necessary. Such distances were thus determined in [41] and recently applied in Maritime Traffic Alert and Collision Avoidance System [42, 43]. Safe distances of evasive actions were also investigated in [44]. Similarly, in [24] a combination of analytical approach with a heuristic (utilizing expert navigators' knowledge) was applied to determine an action zone for a ship. Unfortunately above research either featured only limited number of encounter scenarios or included simplified modelling of ship's dynamics. In [25] these limitations were finally overcome. Those authors assumed manoeuvres of the own ship alone and were interested in determining the last moment of the manoeuvre initiation assuring no collision. That research included an analysis of the own ship's evasive action, which involved trajectory prediction based on the own manoeuvrability-related data. The method was further developed in [26], where stability phenomena were taken into account (avoidance of excessive heel) (Matusiak and Stigler, 2013; Acanfora et al., 2017). The result of both versions of the abovementioned method was a critical distance between the own ship and a target, representing the last moment when a safe manoeuvre had to be performed, A near-zero ship separation was assumed there, following the primary assumption that the own ship is the stand-on one. In practice, a manoeuvre would have to be started considerably earlier if a larger distance between ships should be kept.

A research presented in [25] and the works of their predecessors have inspired the research presented in this paper; however here it is focused primarily on ship domain utilization. We are interested in a time (and a distance, consequently) to a potential collision which still allows us to avoid the specified ship domain violation. What is more, the manoeuvre should fulfil a number of configurable conditions imposed by either COLREGS or a navigator. A considered turn for given close quarter situation should be made on a feasible (depending on the particular encounter) side only, should not exceed a given rudder angle, and should be combined with speed reduction, when necessary.

Another field of researches relevant in terms of our approach deals with a ship manoeuvrability. Although this paper is not intended to push forward modelling of a vessel response to a rudder, a propeller, and external forces, we make use of a ship motion model and this part of our work is one of the key issues. There are two main approaches to the problem of ship manoeuvrability. The first one is based on 
an experiment; however, a significant theoretical background stays behind such tests. The experimental method is a core tool applied for ships testing after their launching or after a major rebuild. There are numerous principles, provided in regulations $[30,39]$ and guidelines, which are related to the required performance of vessels in terms of their manoeuvrability and to the reliable testing procedures [4547]. The manoeuvring trials, which are routinely performed at a ship delivery, play a vital role for ensuring the appropriate performance of ships in terms of turning, stopping, directional stability, etc. However, the test needs to be performed in calm weather, so the behaviour of the ship remains somewhat unknown when facing harsh weather.

The alternative approach to a ship manoeuvrability estimation is theoretical one and nowadays it may be called the numerical modelling. Actually, the experimental methods are based on the theory while the modelling carried out in a virtual environment utilizes results of experiments aiming at determination of a long list of coefficients [48]. Anyway, once the coefficients are established for the hull, the mathematical modelling can be performed for many assumed scenarios. The literature comprises massive number of research works dealing with ship motion modelling. Significant differences can be noticed between various mathematical formulation and numerical solutions presented in scientific works published in last decades. One of the main issues is the number of ship's degrees of freedom taken into account. The simplest approach is based on a 1 DoF equation which may be applied in autopilot control. The $3 \mathrm{DoF}$ differential system is frequently applied to describe the planar motion of a vessel which is often utilized in training simulators $[22,49,50]$. In addition, the 4 DoF model is utilized by some authors to comprise the surge, sway, yaw, and roll coupled motion, neglecting the effect of pitch and heave [51]. For more detailed but consequently less time-effective modelling of a ship motion, the 6 DoF systems are applied [52]. In recent years, also, some CFD-based works are published and this line is promising although still not matured with regard to time efficiency of computations [53]. In this study the 6 DoF model is applied and the core simulations of ship motion are carried out with the use of LaiDyn code developed at Aalto University, Finland.

\section{Determining Action Distances for Evasive Manoeuvres: The Method}

Similarly to $[25,26]$ the paper investigates situations, when the own ship is the stand-on ship. In such cases the situation is different from give-way: the manoeuvre of a target is expected and own manoeuvre is a last resort. However, if the target does not react in due time, the navigator of the own ship may still have to act. While COLREGS state that the standon ship, if needed, can take evasive action, they do not specify when exactly to perform a manoeuvre. In stand-on situations navigators tend to take actions too late, which may lead to rapid and forceful manoeuvres neglecting stabilityrelated issues. It is therefore reasonable to provide them with a tool informing when to start a manoeuvre, depending on the desired separation, which is represented here by a ship's domain. When determining this action distance, it is also important to take into account weather conditions: in severe weather the choice of manoeuvres may be limited and thus the remaining possible actions may have to be taken earlier. The choice of a particular evasive manoeuvre in heavy weather has been discussed in detail in [54]. In the current paper we are mostly interested in when to perform a safe manoeuvre. A scheme of the method determining action distances for stand-on scenarios is presented in Figure 1.

First, the method determines encounter type and action type. Then user-given parameters, ENC data, and weather data are read. Based on the weather data and own ship model, the method determines and stores all combinations of own course and speed which may lead to stability-related phenomena. All of the above information are then used by a gradient algorithm to determine the critical manoeuvre time within a specified interval of considered values (Figure 2). For collision avoidance purposes, the method uses a degree of domain violation (DDV) parameter [55].

The method is able to determine the time (and consequently - the distance) at which the user-specified manoeuvre ought to be performed in order to avoid domain's violation. Its parameters such as the maximal size of course change and (optionally) speed reduction are assumed to be set by the user (here: a navigator). The accuracy of the method and presented simulation results depends on three elements and their respective accuracies:

(i) LaiDyn code responsible for simulating course alteration manoeuvres and also applied to modelling of stability-related phenomena,

(ii) modelling of speed reduction manoeuvres,

(iii) main simulation application.

As for modelling of ship's behaviour, it is discussed in the next section. In general, simulating course alteration manoeuvres and stability-related phenomena is very accurate (due to the LaiDyn code), while the modelling of speed reduction manoeuvres is simplified in comparison. As for the main simulation application, it makes use of some analytical solutions (for determining ship domain-related parameters) and some robust iterative algorithms. Therefore simulation application does not bring any elements, which could affect overall accuracy of the presented method; the final accuracy depends strictly on the already mentioned accuracies of modelling ship's behaviour and the human reaction time (which is taken into account as a value set by a user).

A separate complementary decision support tool enabling the navigator to choose a particular manoeuvre has been presented by the authors in [56] and then extended to deal with heavy weather in [54].

\section{Model of Ship's Manoeuvrability Used in the Method}

4.1. Contemporary Simplest Approach to Ship Manoeuvring Characteristics Application at the Stage of Collision Avoidance Planning. Due to safety reasons deck officers must be aware 


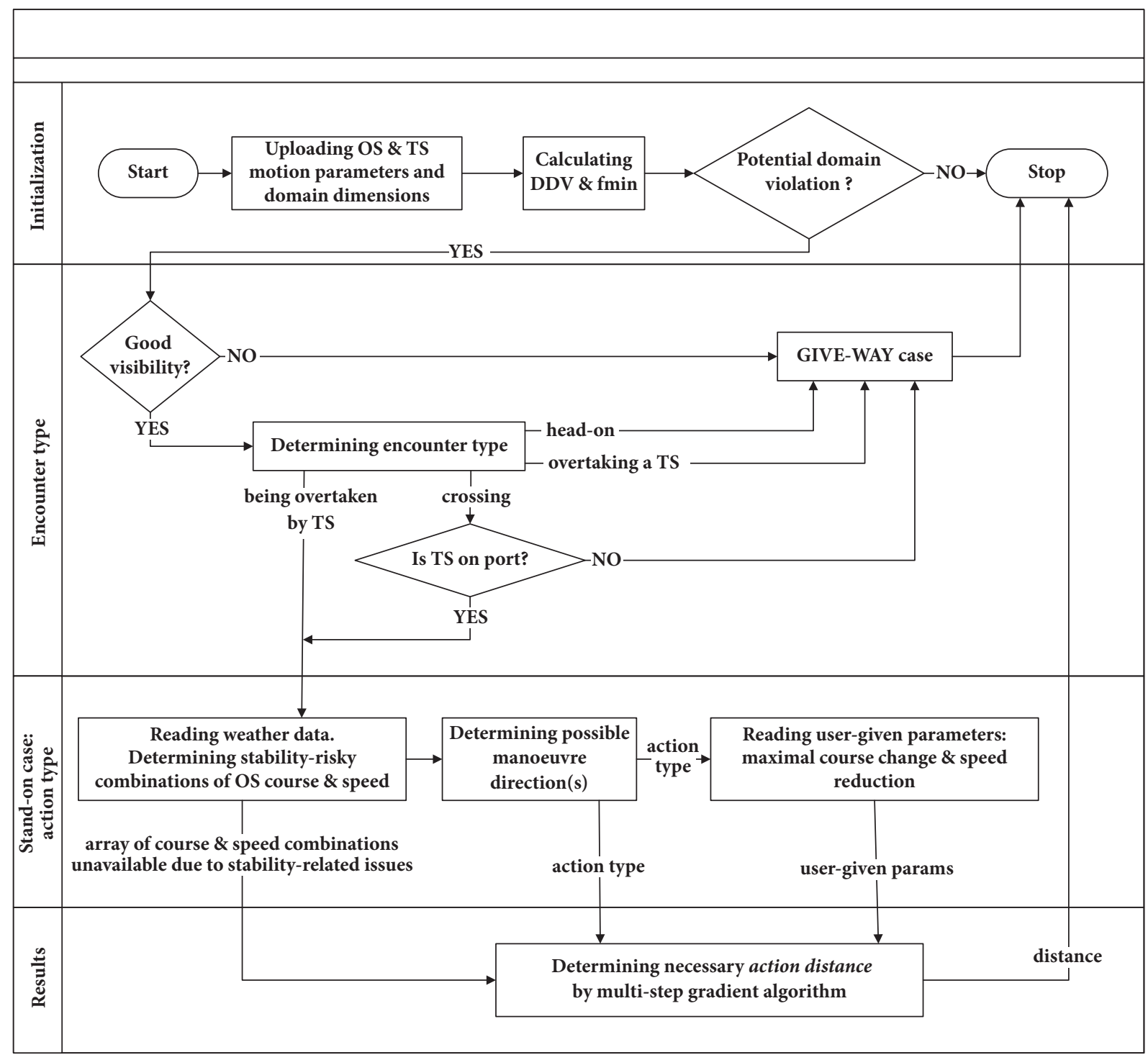

FIGURE 1: Determining distance necessary for avoiding domain violations in stand-on situations.

of manoeuvring characteristics of the own vessel. Therefore, such characteristics are routinely determined during sea trials at the end of the ship building process and then are given for further use in the form of a wheelhouse poster. The turning circles for the maximum rudder settings (hard to port and hard to starboard) are plotted and aside from the tactical and final diameter also the advance and transfer characteristics are given there (usually for ballast and fully loaded conditions). An example of such characteristics is given in Figure 3.

It should be emphasized though that the wheelhouse poster presents turning circles valid when sailing in still water and ordering the rudder hard to port or starboard. However, the maximum rudder angle rarely is applied in practice except for the "last chance" manoeuvre, which shall be avoided at all owing to advance planning of evasive actions. The thorough study on the influence of ships manoeuvring characteristics was presented in [25].
The typical approach when analysing the collision avoidance is the use of bridge simulator and the predefined ship characteristics corresponding to the wheelhouse poster data. A sample turning circle is presented in Figure 4.

The application of the bridge simulator enables virtual tracking of vessels encounters and determination of the critical distance as shown in a sample case in Figure 5.

The awareness of the critical distance being marginal for the "last chance manoeuvre" remains of great importance for navigators; however, turning hard cannot be found as a standard procedure to avoid collision. Moreover, such hard turning could be sometimes completely irrelevant due to excessive heel expectations due to tender stability of a ship [26]. Thus, the realistic trajectories of turning vessel should be obtained for an applicable range of rudder angles to definitely avoid replacing of hazards to navigation (collision or near miss) to hazards to stability (capsizing or excessive heel). 


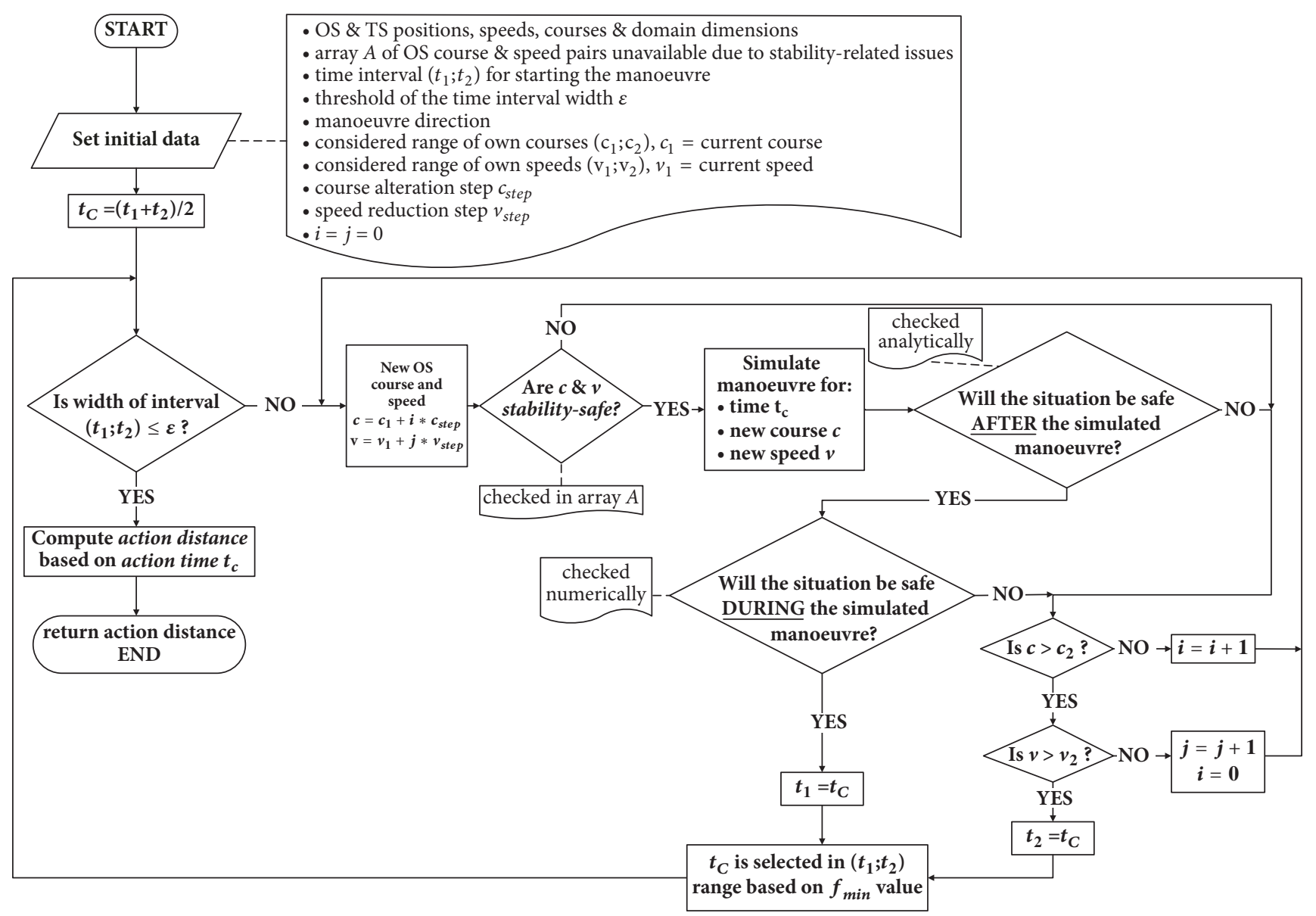

FIGURE 2: A multistep gradient algorithm returning time, when a manoeuvre should be started in a stand-on situation.

The utilization of the full mission bridge simulator is found by the authors as questionable, despite its indubitable usefulness in the course of deck officers training. Such simulators do not perform real-time computations of ship motion under the set external conditions. The ship motion is based rather on a simplified mathematical model, without taking into account actual wave field nature and ship stability conditions. The displayed rolling is more for visual perception than for the purpose of exact dynamic stability phenomena determination.

The conclusion is that the wheelhouse poster and any further applications of data provided by it, although essential in terms of a last chance manoeuvre, do not meet the requirements of routine collision evasive action. Therefore, another solution needs to be applied.

4.2. 6 DoF Modelling of Ship Motion. Since the intention is to model and analyse quite complex ship behaviour including ship response on wave action and nonlinear stabilityrelated phenomena, the authors have decided to utilize a sophisticated numerical tool instead of a bridge simulator. The applied software tool LaiDyn has been chosen, able to simulate ship motions in six degrees of freedom with regard to all significant phenomena governing her resultant trajectory, e.g., a ship shape (hull geometry), rudder and propulsion action, and an impact of external environment (wind and wave action). The tool has also been positively validated during the ITTC benchmark studies $[47,57,58]$. The LaiDyn simulations carried out in time domain comprise irregular seas effects and the direct impact of rudder and propeller since the kinematics of water flow in waves is taken into account when evaluating the resultant thrust [59], which is beneficial for this research.

The nonlinear components are implemented and the Froude-Krylov forces, the diffraction forces (these two relate to wave action), and the radiation forces are considered. The first is computed by integrating the water pressure over the wetted panels of the hull and the nonlinear approach is utilized. The diffraction forces, in turn, are evaluated according to the linear model. The radiation forces comprising added mass and damping terms take into account the history of the previous motions by applying the memory function. The detailed description of the LaiDyn tool is thoroughly presented in [59]. The model of ship dynamics which is utilized for the purpose of the research is able to estimate the realistic resultant trajectory during turning with regard to complex hydrodynamic effects. The following phenomena are considered by the LaiDyn code: 


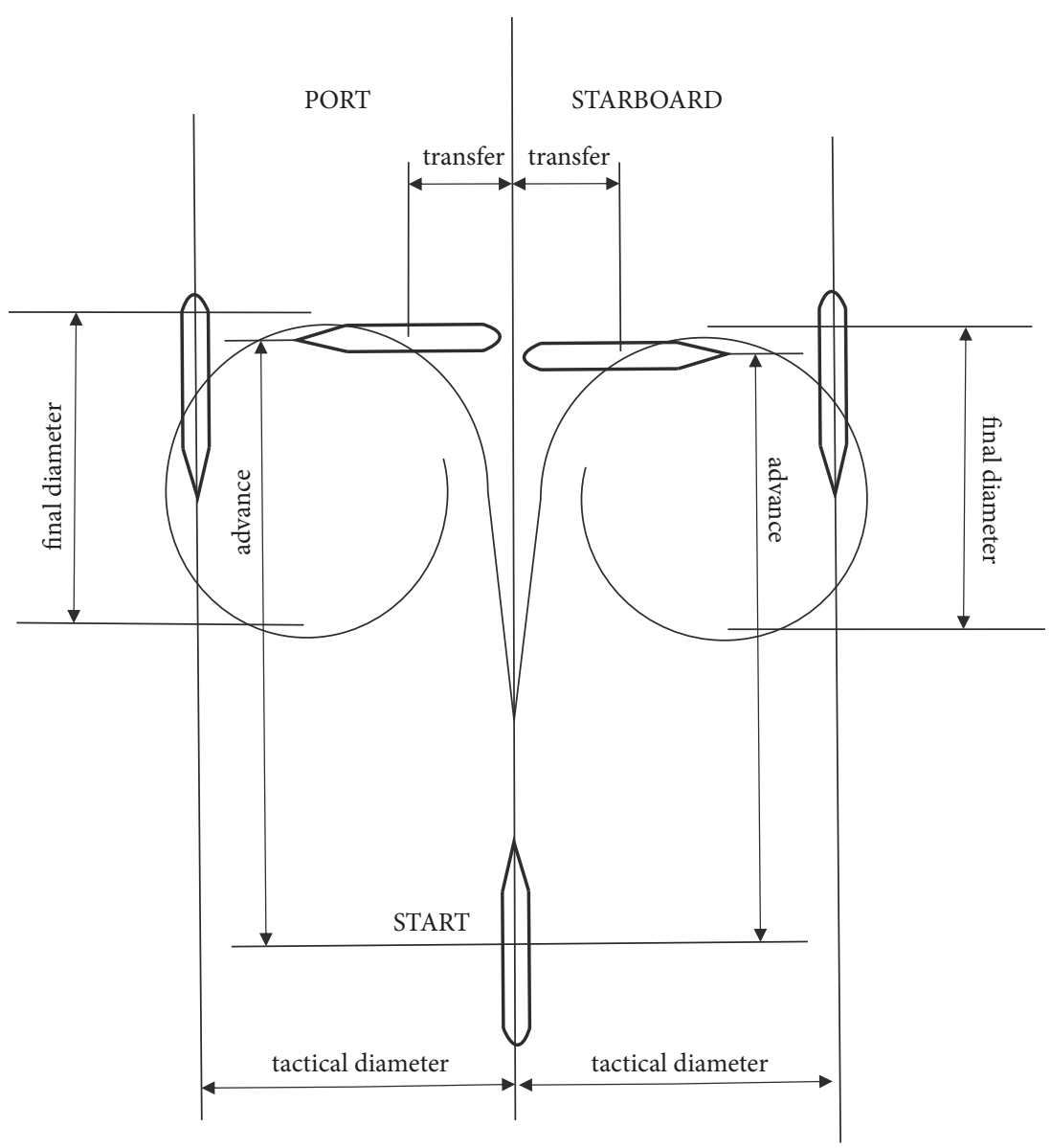

FIGURE 3: Typical graphical presentation of ship manoeuvrability characteristics available on board in the form of a wheelhouse poster (the sketch taken from didactical materials for students of the Faculty of Navigation, Gdynia Maritime University).

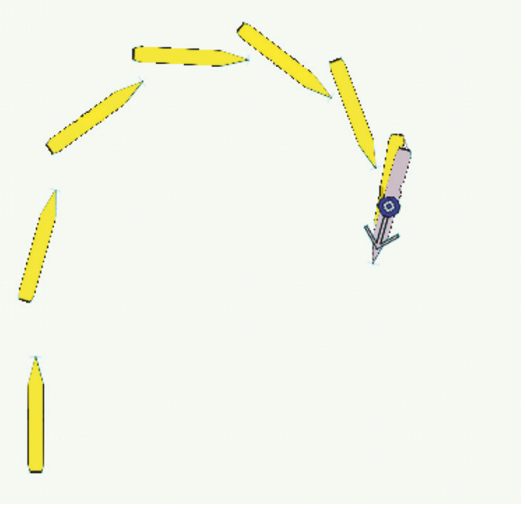

FIGURE 4: Simulation of sample ships turning performed with the use of the full mission bridge simulator at the Faculty of Navigation, Gdynia Maritime University.

(1) Regardless the rate of turn (in both conditions, straight steaming and turning):

(i) effects of the ship motion in all six degrees of freedom including the boundary layer, creating the added mass of water to be dragged; (ii) the added resistance due to seas action resulting in loss of speed.

(2) Additional effects arousing during turning:

(i) the skew and asymmetrical pattern of water inflow into the propeller surrounding resulting in propulsion effectiveness reduction;

(ii) additional resistance due to asymmetrical wave system generated by the hull when turning.

Similarly to an earlier work [60] the LaiDyn code is utilized in our research to obtain the simulated trajectories of the ship during turning. The various rudder settings (10; 20; 30 degrees to port and 10;20; 30 to starboard) are applied for in the curse of performed numerical computations. All simulations take into account the $\mathrm{a} / \mathrm{m}$ effects in quite heavy seas since the wind force is set to 8 Beaufort and the corresponding wave system are considered. Thus, the influence of seas action is noticeable comparing to calm water conditions.

Wind force is about 8 on Beaufort scale and the corresponding wave system is considered. The ship taken into account is a mid-size ro-pax, whose particulars are as given in Table 1. 
TABle 1: Parameters of the ro-pax ship used throughout the simulations.

\begin{tabular}{lc}
\hline Parameter name & Parameter value \\
\hline Length between perpendiculars LPP [m] & 158 \\
Breadth B [m] & 25 \\
Draft d [m] & 6.10 \\
Hull's height H [m] & 15 \\
Displacement D [t] & 14152 \\
Wetted surface S [m2] & 4356 \\
Block coefficient CB [-] & 0.571 \\
Initial metacentric height GM [m] & 1,90 \\
Service speed [kn] & 17 \\
\hline
\end{tabular}

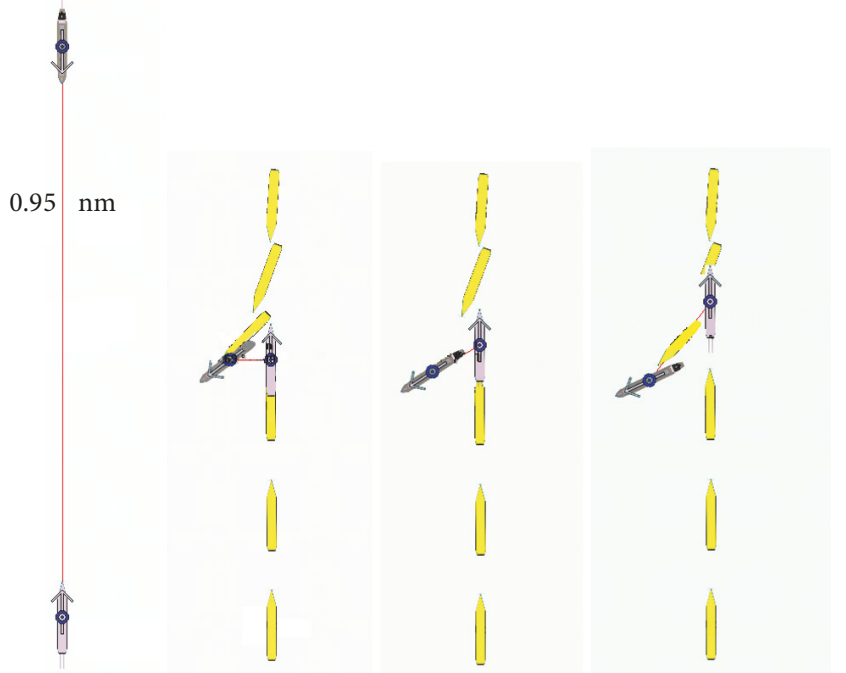

FIGURE 5: Virtual tracking of sample vessels encounter and determination of the critical distance performed with the use of the full mission bridge simulator.

Both the obtained trajectories and the rate of turn (RoT) are essential for evasive manoeuvre planning procedure. Thus, the turning circles and RoT plots are presented as a result of LaiDyn simulations for the model ship and rudder settings 30, 20, and 10 degrees in Figures 6, 7, and 8, respectively. Then based on obtained simulation result, the metamodel is created to enable fast processing in the main algorithm dealing directly with collision evasive manoeuvre planning.

For the sake of simplicity and time savings we have decided to carry out the series of the ship slowing down simulations with the use of significantly less complex code prepared in Matlab environment instead on LaiDyn. Slowing down to avoid collision is rather rare manoeuvre; therefore it is not so essential to take into account all the effects like in case of turning. According to the COLREGS Rule 8 (action to avoid collision) "if there is sufficient sea-room, alteration of course alone may be the most effective action to avoid a closequarters situation provided that it is made in good time (...)"; however the ship speed reduction is alternatively accepted manoeuvre for the purpose of collision avoidance. Thus, the simplified numerical simulation of the considered ro-pax speed reduction has been carried out. The initial speed is set to the service 17 knots and then after 100 seconds of steaming the propeller thrust is gradually decreased down to the power reflecting 4 knots of speed. The decrease in thrust takes 2 minutes and then it remains constant. The resultant speed reduction is slower than thrust reduction since inertia of the ship pushes her forward, observably. The result of the simulation for the modelled ship is shown in Figure 9.

Generally ship's action to avoid collision should be not only effective but also clear to others and easy to recognize for surrounding ships using ARPA radar, while the speed reduction is not. According to the simulation result, the drop of speed takes more than 10 minutes and, what is worse, it is gradual and difficult to instant acquisition. Nevertheless, sometimes the reduction of speed can be the most reasonable solution; thus such manoeuvres are considered feasible in the presented research.

The results of both the turning and the speed reduction simulations are transferred into the form of metamodels using the polynomial power series as follows:

(1) Speed reduction is as follows:

$$
V_{t}=\sum_{i=1}^{9} s_{i} \cdot t^{i-1}
$$

where $s_{i}$ are coefficients of the polynomial model and $t$ is the time from the speed reduction manoeuvre initiation.

(2) Turn

$$
\begin{aligned}
X_{t} & =\sum_{i=1}^{6} p_{i} \cdot t^{i} ; \\
Y_{t} & =\sum_{i=1}^{6} q_{i} \cdot t^{i} ; \\
\text { heading } r e l_{t} & =\sum_{i=1}^{5} r_{i} \cdot t^{i}
\end{aligned}
$$

where $X_{t}$ and $Y_{t}$ denote the position of ship's centre of gravity as functions of time; heading_rel $l_{t}$ is the relative heading at any time moment, taking the initial heading at the manoeuvre commencing as zero; $t$ is time of the turning manoeuvre (continuous variable in the metamodel); $p_{i}, q_{i}$, and $r_{i}$ are 

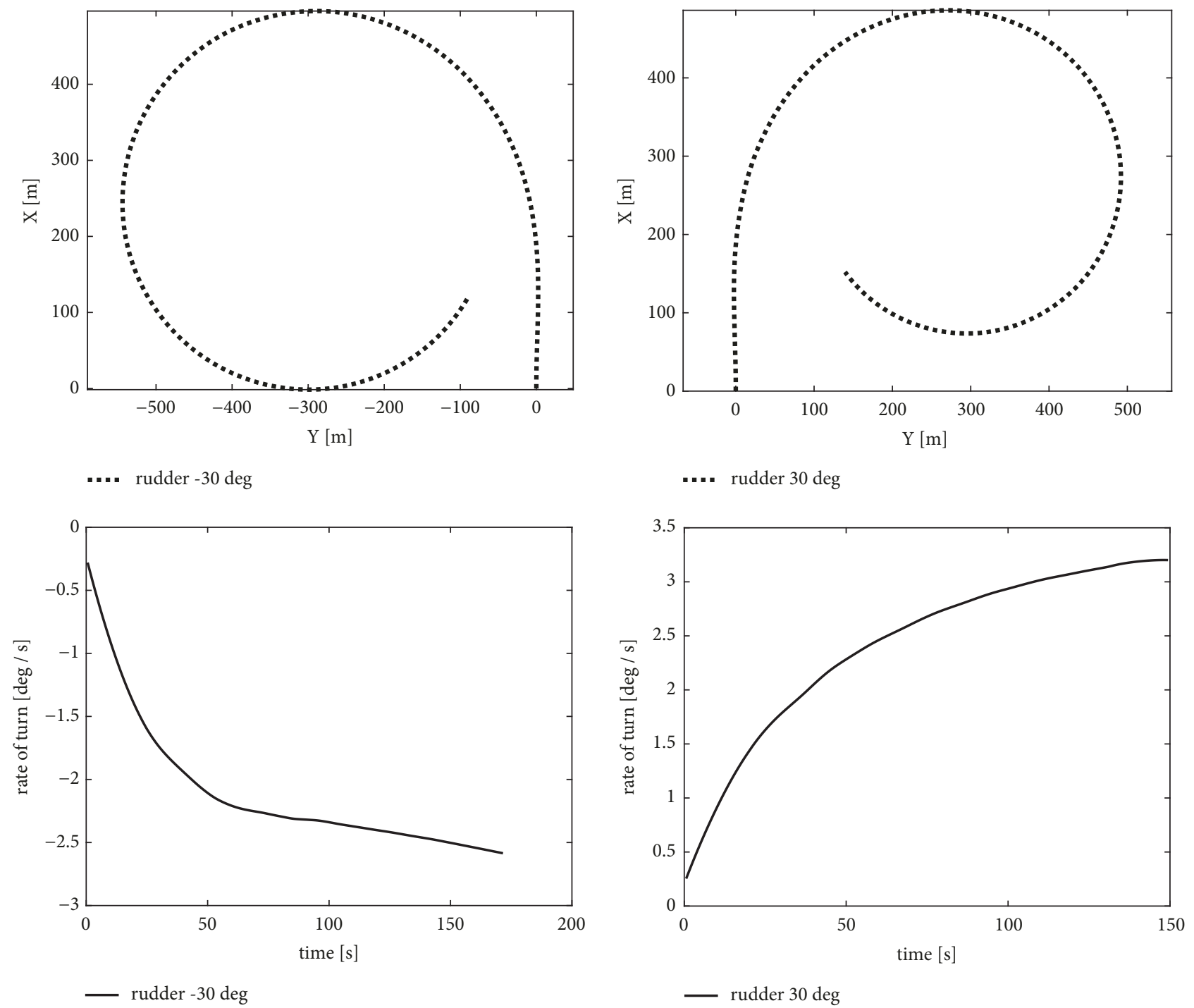

FIGURE 6: Results of LaiDyn simulations for the considered ro-pax for rudder setting 30 degrees.

the model coefficients adjusted with the use of least squares method.

The applied order of each polynomial results from the goodness of fit analysis performed with the use of Matlab system. The effort required to obtain 5-th, 6-th, and 9-th order polynomials is apparently the same since the fitting procedures are fast and effective. Also from the planned utilization point of view there is no significant difference between these polynomials and the time of execution of the main algorithm is very similar regardless the order of polynomials being the metamodels of speed reduction and vessel track. Thus, the best fitted curves are finally applied regardless their order.

It should be emphasized that the time-consuming simulations, which require some sophisticated computations, need to be done once only and their results are input to the evasive manoeuvre planning algorithm. Then the algorithm utilizes the metamodels (1) and (2) which enable fast computation and practical implementation of the solution presented in this paper.

\subsection{Simplified Time-Effective Modelling of Nonlinear Stability-} Related Phenomena. Ship stability issues are essential in terms of trajectory planning at every stage of navigation. The long-range optimal route planning benefits from an integration of typical weather routing with stability-origin goal functions and restrictions [61]. Similarly, the shortest range planning of the ship trajectory may profit thanks to close relation of the collision evasive manoeuvre objectives with stability-related ones. The main purpose of such integration is the holistic approach to the ship safety, which is intended to strictly avoid swapping one hazard into another one, especially since navigators are not aware of. Thus, any established solution of a collision situation which provides keeping clear off all vessels, ought to be rejected and find unsafe if it exposes own ship to serious hazard resulting 

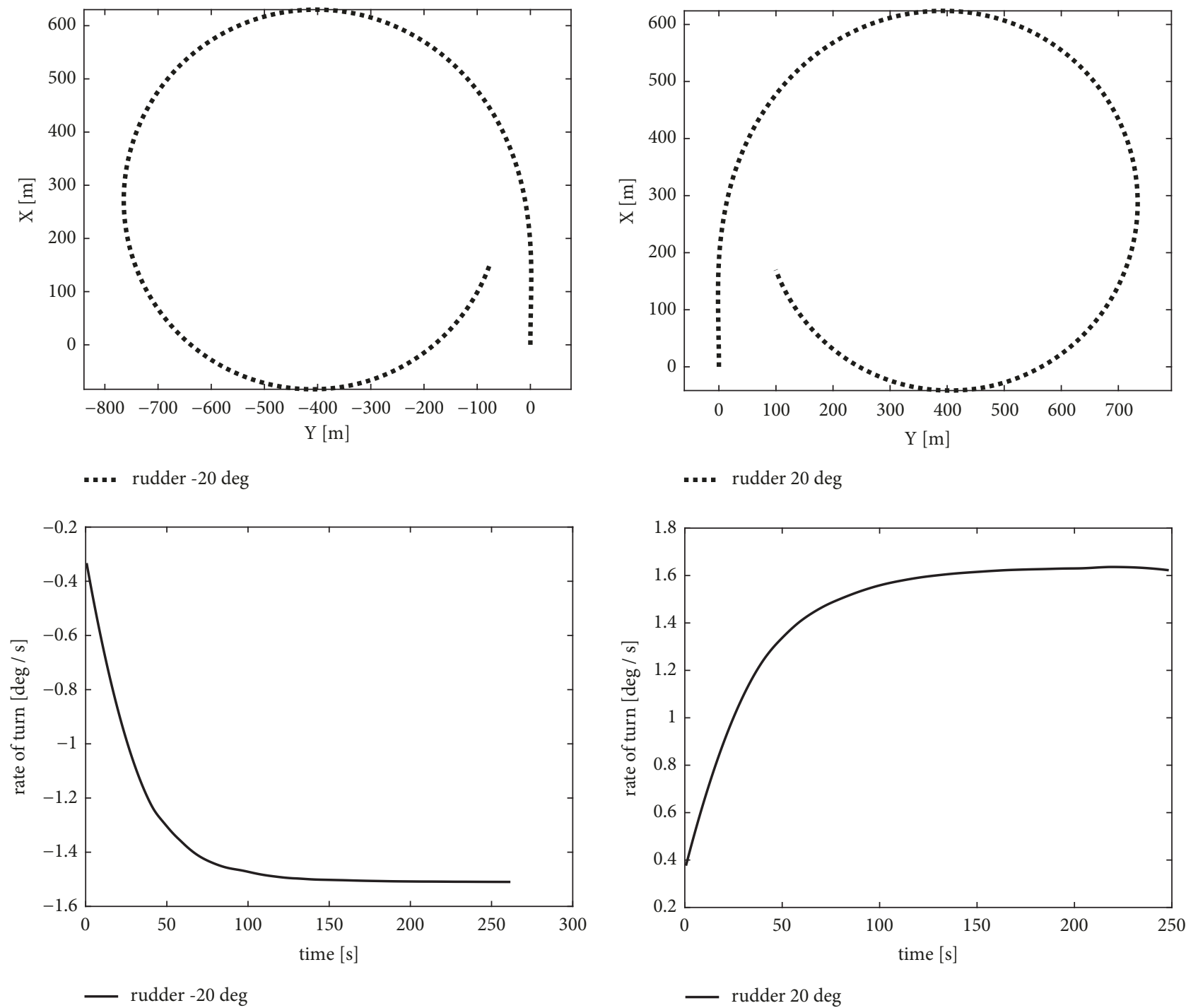

FIGURE 7: Results of LaiDyn simulations for the considered ro-pax for rudder setting 20 degrees.

from stability-related phenomena. The exemplary case would be the ship course alternation leading to the new heading, which results in well tuning of the natural period of ship's roll and the encounter wave period. The aftermath would be the strong nonlinear gain of ship rolling which may cause slip of containers, bulk cargo shift and similar incidents depending on the type of a vessel. Such an evasive action is identified as unacceptable in this study, even if the action would be effective from the ship manoeuvring characteristics point of view.

The revealed need for integration of the ship stability and evasive action planning requires an adoption of a model enabling the ship response prediction. The $6 \mathrm{DoF}$ motion model, making extensive use of LaiDyn code which is presented in Section 4.2, provides accurate results with regard to complex motion of the ship. As LaiDyn comprises all essential forces governing ship dynamics, it is able to cover the resonant rolling as well, and it does. The potentially dangerous phenomena like synchronous rolling and parametric resonance are reflected in the simulation results appropriately.

Considering LaiDyn performance one could expect a direct application of this code to every single case of collision situation to be solved. Unfortunately, such an approach is not time-effective. We do not directly apply LaiDyn to manoeuvring, preparing the metamodel instead (Section 4.2), and consequently the next metamodel comprising stability-related phenomena needs to be worked out. Moreover, due to strongly nonlinear response of a ship when rolling in waves the required number of simulations would be massive. The problem is not burdensome in case of developing of the manoeuvring metamodel since the sensitivity of the ship on the wave spectrum is limited. Contrary to this, the dynamic stability-related phenomena are highly nonlinear and very sensitive to the actual wave characteristics. Thus, it is not feasible to obtain a simple model of ship response to any wave action, which may be spotted in practice. Facing this difficulty we decided to apply 

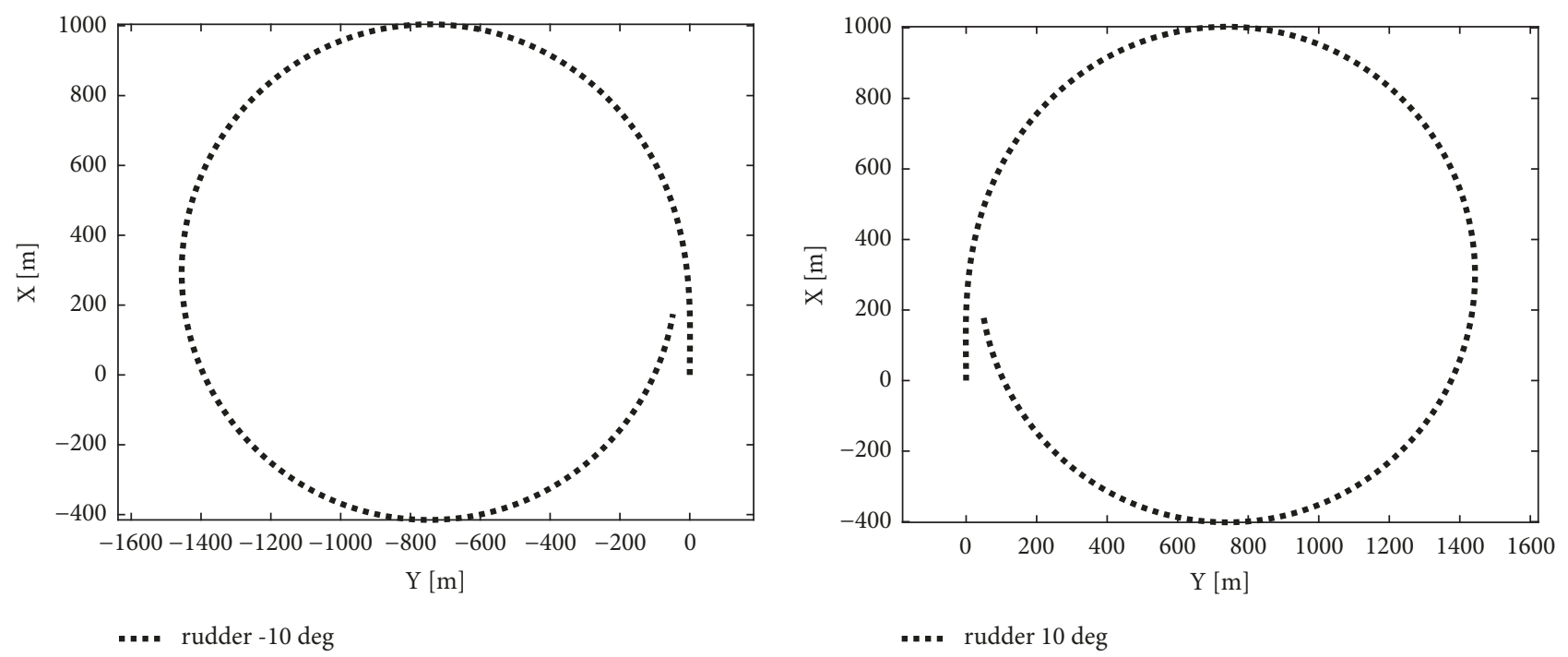

.... rudder $10 \mathrm{deg}$
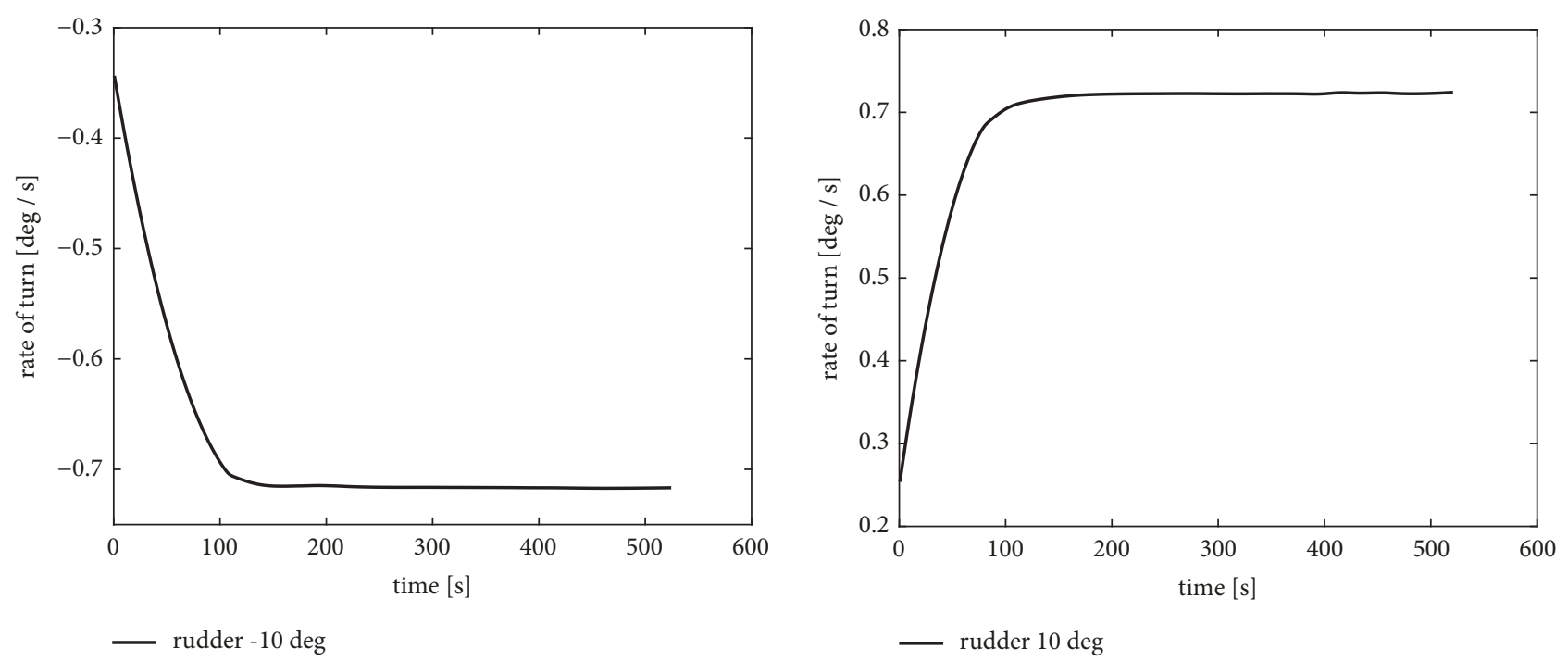

FIGURE 8: Results of LaiDyn simulations for the considered ro-pax for rudder setting 10 degrees.

the simplified approach based on recommendations included in the revised guidance to the master for avoiding dangerous situations in adverse weather and sea conditions (IMO document numbered MSC.1/Circ.1228) instead of 6 DoF modelling. This makes the proposed method time efficient and therefore practically applicable on board. The revised guidance is intended to give significant help to shipmasters when sailing in stormy conditions. This publication contains a set of direct remarks and advices regarding the avoidance of following dangerous dynamical phenomena at sea like surf-riding and broaching-to, reduction of intact stability when riding a wave crest amidships, synchronous rolling, and parametric roll motions (IMO, 2007).

Our intention is to plan the collision evasive action and any other manoeuvre with regard to both COLREGS rules and dynamic constraints resulting from the ship stability characteristics related to actual sea state. Thus, for the purpose of this work we do not focus on distinguishing the specific stability problems, providing rather concise information related to permitted and banned configuration of course and speed without explicit identification of synchronous rolling, parametric resonance, and others based on simplified approach recommended by IMO in the guidance MSC.Circ. 1228.

\section{Method's Simulations for Stand-On Scenarios}

This section presents results of simulations performed to determine the area, not to be intruded by a target (in line with the paper's aim). A decentralised elliptic domain from Figure 10 has been applied for stand-on crossing encounters (with $x=L$ ) and for being overtaken (with $x=0$ ).

The domain above is roughly based on [3], though the dimensions are more in line with recent research $[8,9]$.

The own ship model from Section 4 has been applied to determine action lines $[36,37]$. It has been assumed that a single target approaches the own ship from various relative 


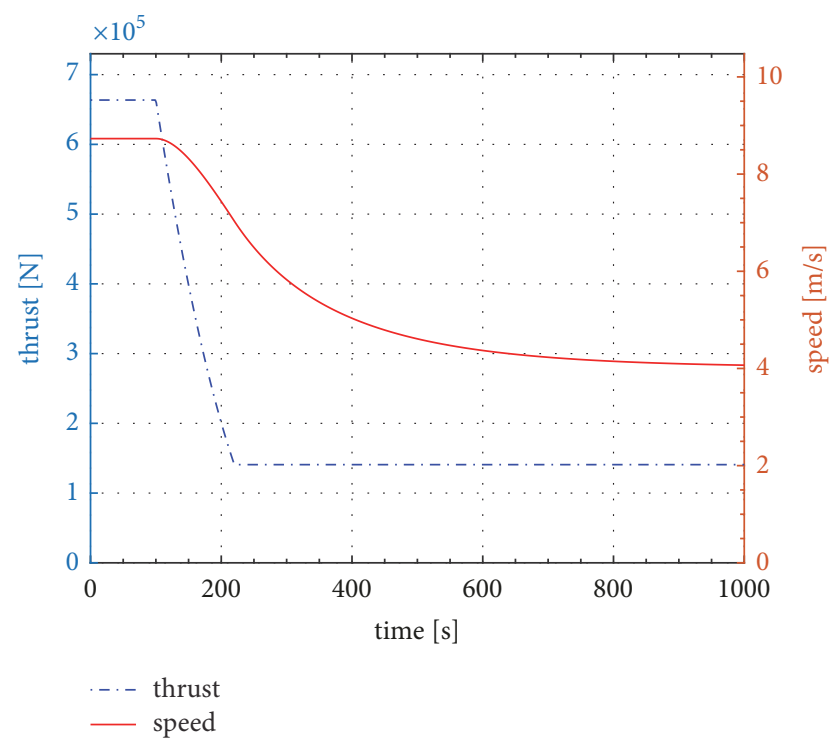

FIGURE 9: Simulated slowing down of considered ro-pax (range from service speed $17 \mathrm{kn}$ down to $4 \mathrm{kn}$ ensuring ability to manoeuvre).

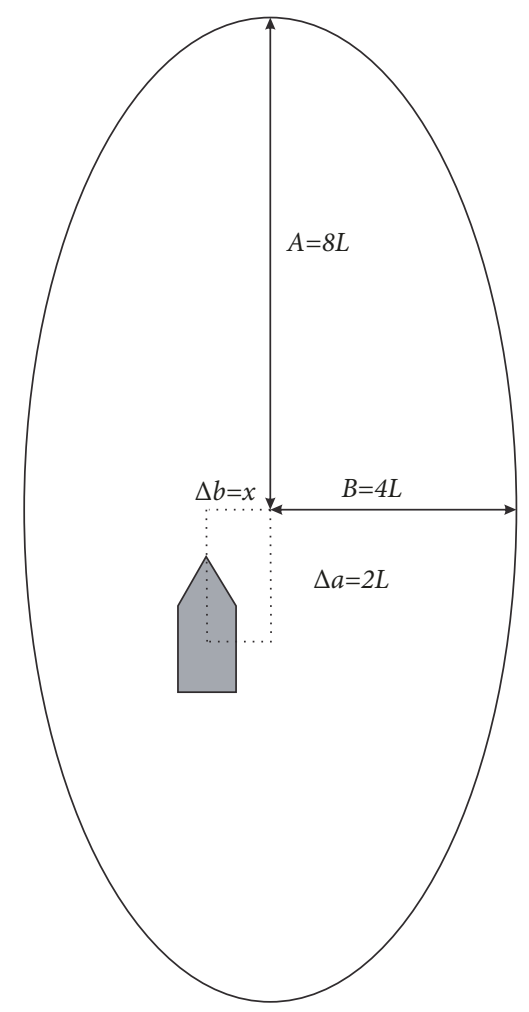

FIGURE 10: Length-dependent ship's domains applied in the simulations: $x=L$ for stand-on crossing encounter and $x=0$ for being overtaken.

bearings: up to 7200 target's relative bearings have been used to generate a full action line around the own ship.

In Figures 11 and 12 full action lines around the own ship (ship arenas) are depicted to provide general results in a concise form. Exemplary target's positions are shown there.

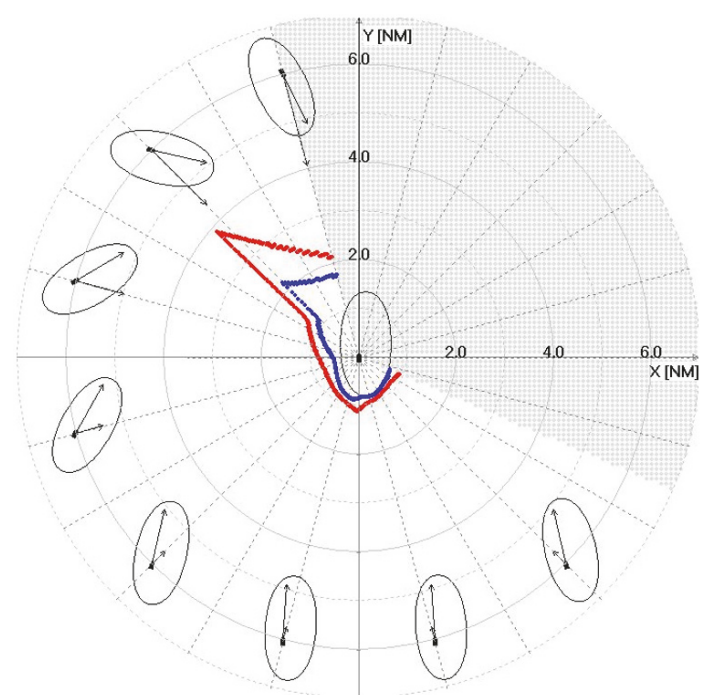

FIGURE 11: Own ship's arenas for a target approaching with a true speed of 18 knots (blue line) or 23 knots (red line) in good visibility. Course alterations of up to $90^{\circ}$ to starboard are considered for crossing, course alterations to either side for being overtaken. No speed reduction is assumed.

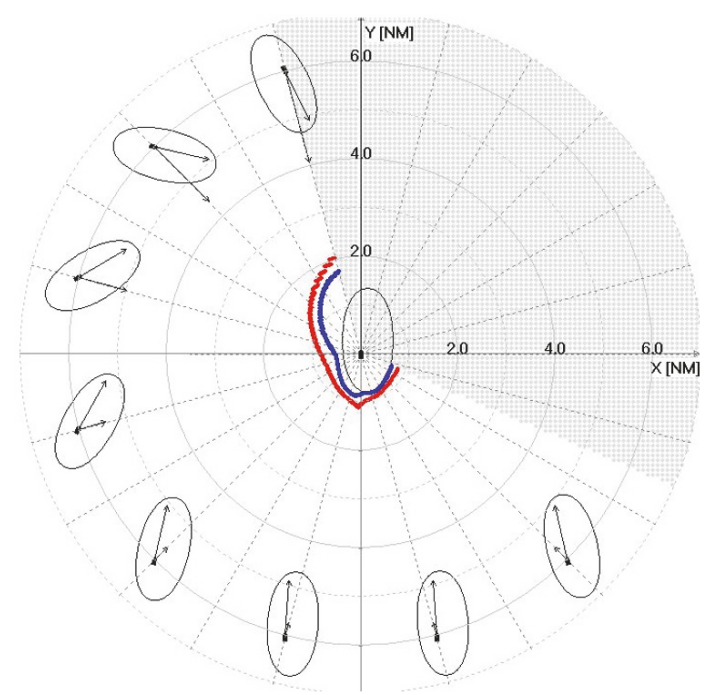

FIGURE 12: Own ship's arenas for a target approaching with a true speed of 18 knots (blue line) or 23 knots (red line) in good visibility. Course alterations of up to $180^{\circ}$ to starboard are considered for crossing, course alterations to either side for being overtaken. No speed reduction is assumed.

True speed of a target has been applied and manoeuvres have been determined in compliance with COLREGS (Rule 15):

(i) to starboard only for crossing;

(ii) to either side (depending, which turn would be easier to perform) in case of being overtaken.

The figures illustrate two dependencies. First: action line is changing with the true speed of a target (blue line for 18 knots, red one for 23 knots). Second: action line is heavily 


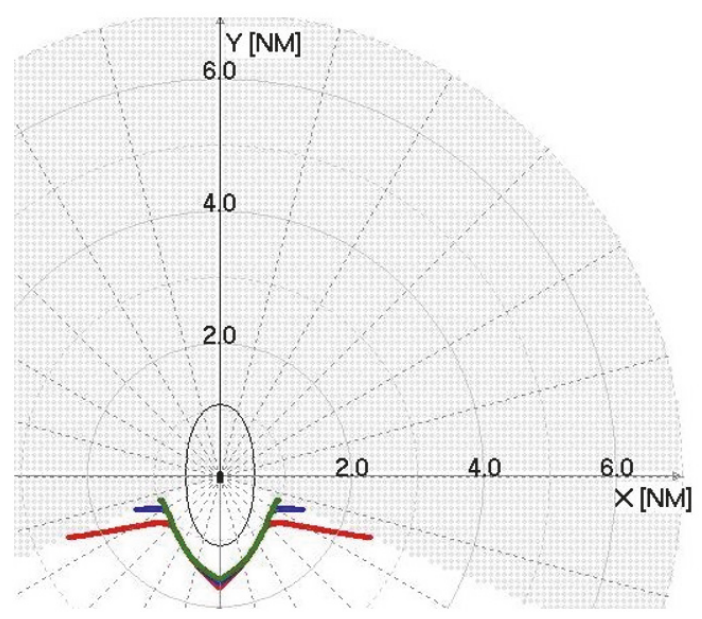

FIGURE 13: Action lines for being overtaken by a target, whose true speed is 23 knots. Turns to both sides are considered depending on target's relative bearing. Turns are limited to $15^{\circ}$ (red), $20^{\circ}$ (blue), and $60^{\circ}$ (green). No speed reduction.

affected by the maximum size of the planned manoeuvre $\left(90^{\circ}\right.$ in Figure $11 ; 180^{\circ}$ in Figure 12).

Figure 11 reveals that manoeuvres to starboard for targets on relative courses around $45^{\circ}$ on starboard require much earlier action to avoid domain violation (especially if the target is significantly faster than the own ship). However, applying larger turns can reduce action lines considerably (Figure 12).

5.1. Being Overtaken by Another Ship. If the own ship is to be overtaken by a target, it is the target that is supposed to perform an appropriate manoeuvre. However, if the target does not act accordingly, the own ship's navigator may be interested in his continuously diminishing options considering evasive action. The target's speed has been set to 23 knots, to make it significantly larger than the own speed of 17 knots. Below it is shown at what distance the own ship might still make a manoeuvre to avoid domain violation, if the target keeps its course unchanged. If turns to both sides are considered (Figure 13), a 15-degree turn is enough to avoid domain violation for an action distance of $2.8 \mathrm{NM}$, a 20 degree turn can shorten the action distance to about $1.5 \mathrm{NM}$ and a 60-degree turn - to 1.2 NM. Alternatively, the evasive action may be started at a distance of $2 \mathrm{NM}$, if a 15-degree turn is combined with a 3-knot speed reduction (Figure 14). Interestingly, further reduction of speed does not bring any significant progress in that matter.

It is worth noting that it is much harder to avoid domain violation by turning towards a target behind, as evidenced by Figures 15 and 16, where action distances for manoeuvres to starboard are shown. The distances are relatively small for targets on port side and much larger for targets on starboard. Manoeuvres by course alteration alone are highly inefficient here (Figure 15): it takes a turn of 120 degree to avoid domain violation, when the target is $3 \mathrm{NM}$ away from the own ship or a turn of $150^{\circ}$ at a $2.5 \mathrm{NM}$ distance. Combinations of turns

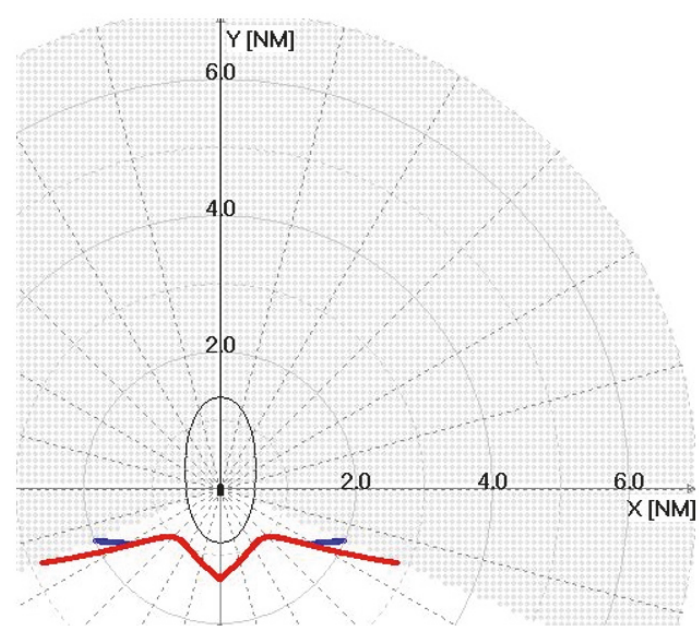

FIGURE 14: Action lines for being overtaken by a target, whose true speed is 23 knots. Turns to both sides are considered depending on target's relative bearing. A turn of $15^{\circ}$ without speed reduction (red) and with a $3-k n o t$ reduction (blue) is compared.

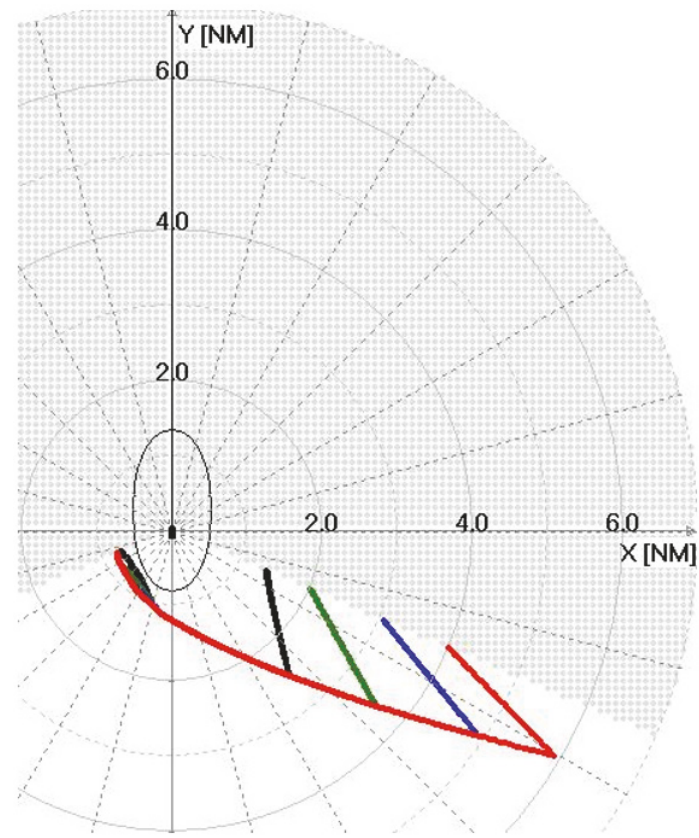

FIgURE 15: Action lines for being overtaken by a target, whose true speed is 23 knots. Assumed are turns to starboard by $90^{\circ}$ (red), $100^{\circ}$ (blue), $120^{\circ}$ (green), and $150^{\circ}$ (black). No speed reduction.

and speed reduction are much more efficient (Figure 16): a 15-degree turn can be safely made at a $3.5 \mathrm{NM}$ or $2.5 \mathrm{NM}$ distance, if it is combined with a 3 -knot or 6-knot speed reduction, respectively.

5.2. Stand-On Crossing. This type of encounter is similar to being overtaken in that the target is supposed to perform an appropriate manoeuvre. Evasive actions of the own ship are a last resort, nevertheless they may be necessary if the target does not give way. Manoeuvres to starboard only are 


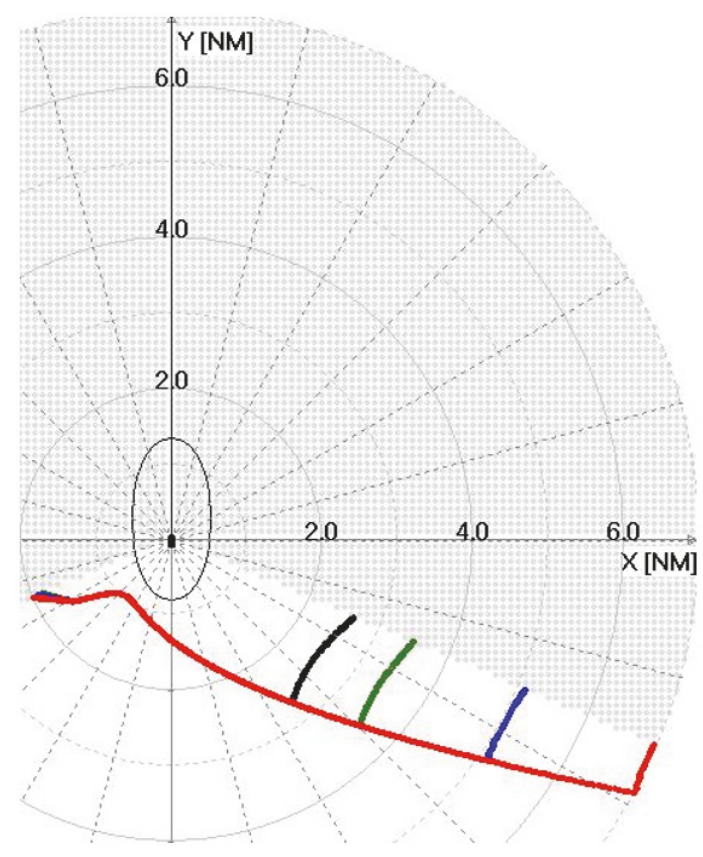

Figure 16: Action lines for being overtaken by a target, whose true speed is 23 knots. Assumed are turns of $15^{\circ}$ to starboard without speed reduction (red) or with speed reduced by 3 knots (blue), 6 knots (green), and 9 knots (black).

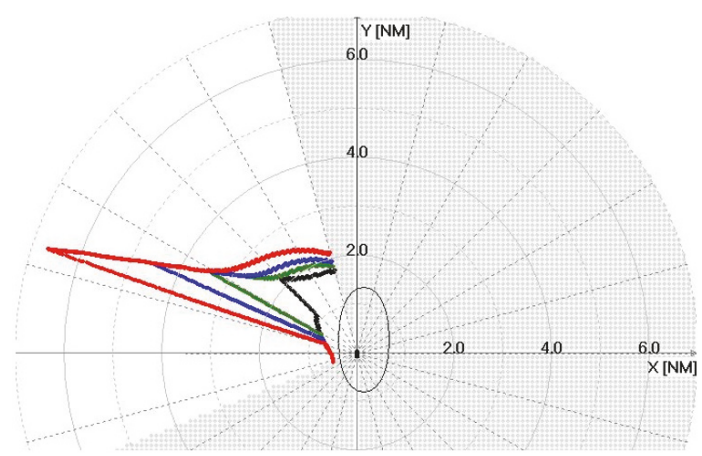

FIGURE 17: Action lines for stand-on crossing encounter with a target, whose true speed is 18 knots. Assumed are turns to starboard by $40^{\circ}$ (red), $50^{\circ}$ (blue), $60^{\circ}$ (green), and $90^{\circ}$ (black). No speed reduction.

considered (for compliance with Rule 17 of COLREGS) and the simulation shows that they have to be quite large unless they are made at long distances (which is unlikely for a standon ship). For a target's true speed of 18 knots, a 60 -degree turn can be safely made at a $3 \mathrm{NM}$ distance or a 90 -degree turn at a $2 \mathrm{NM}$ distance (Figure 17). A 40-degree turn can also be made for $3 \mathrm{NM}$ distance action distance, if it is combined with a 6-knot speed reduction (Figure 18). If the target's speed is 23 knots, a 120 degree turn may be necessary at a 2 NM distance (Figure 19). Speed reduction brings only minor progress in this case, not enough for a much smaller turn $\left(65^{\circ}\right)$ to allow a short action distance (Figure 20).

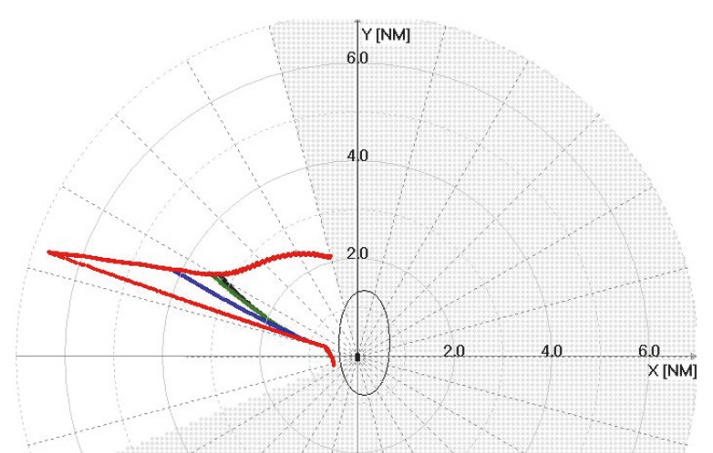

FIgURE 18: Action lines for stand-on crossing encounter with a target, whose true speed is 18 knots. Assumed are turns of $40^{\circ}$ to starboard without speed reduction (red) or with speed reduced by 3 knots (blue), 6 knots (green), and 9 knots (black).

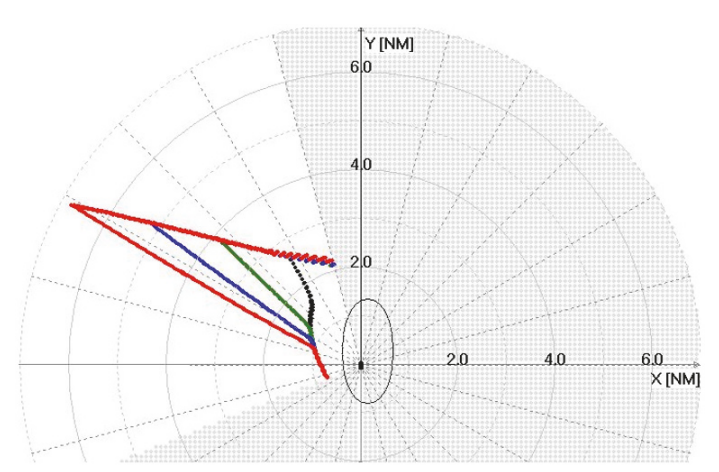

FIGURE 19: Action lines for stand-on crossing encounter with a target, whose true speed is 23 knots. Assumed are turns to starboard by $65^{\circ}$ (red), $75^{\circ}$ (blue), $90^{\circ}$ (green), and $120^{\circ}$ (black). No speed reduction.

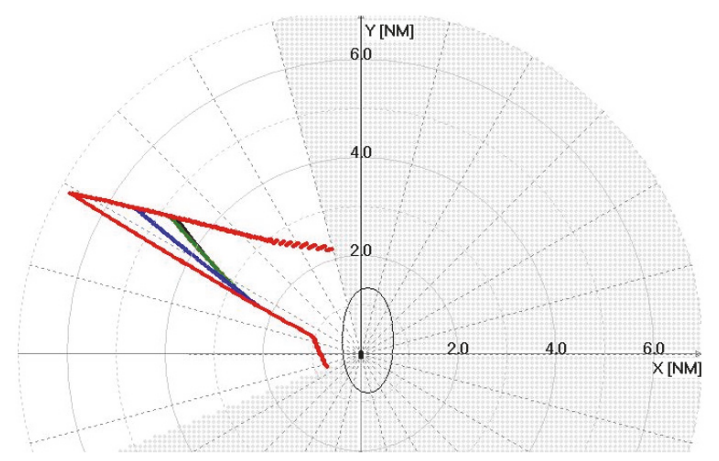

FIgURE 20: Action lines for stand-on crossing encounter with a target, whose true speed is 23 knots. Assumed are turns of $65^{\circ}$ to starboard without speed reduction (red) or with speed reduced by 3 knots (blue), 6 knots (green), and 9 knots (black).

The situation is easier to solve for targets on relative bearings far from traverse. If the target's speed is 18 knots, a 45-degree turn can be made at about 2-2.5 NM distance (Figure 21). However, for target's speed of 23 knots, even a 60-degree turn is not sufficient unless done at about 35 NM distance (Figure 22). Unfortunately, it has also been 


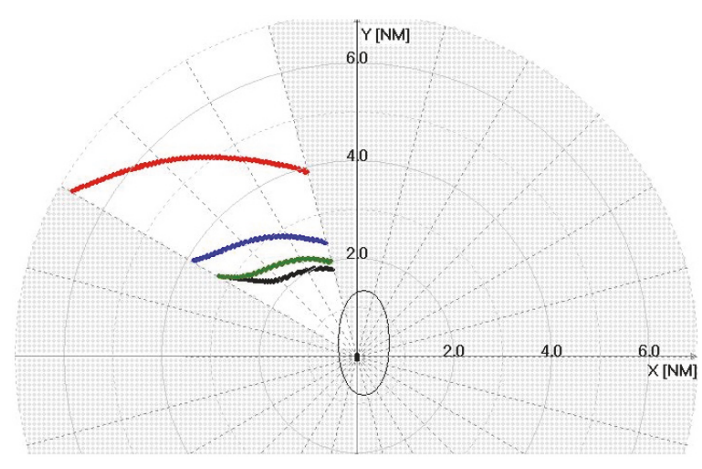

Figure 21: Action lines for stand-on crossing encounter with a target, whose true speed is 18 knots. Assumed are turns to starboard by $15^{\circ}$ (red), $30^{\circ}$ (blue), $45^{\circ}$ (green), and $60^{\circ}$ (black). No speed reduction.

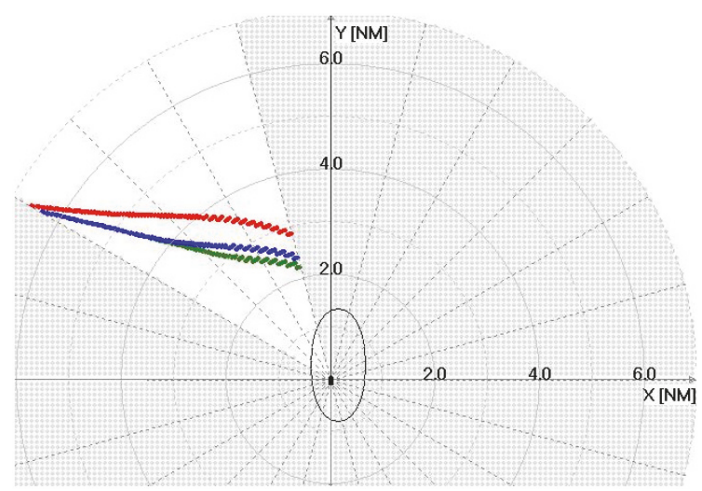

Figure 22: Action lines for stand-on crossing encounter with a target, whose true speed is 23 knots. Assumed are turns to starboard by $30^{\circ}$ (red), $45^{\circ}$ (blue), and $60^{\circ}$ (green). No speed reduction.

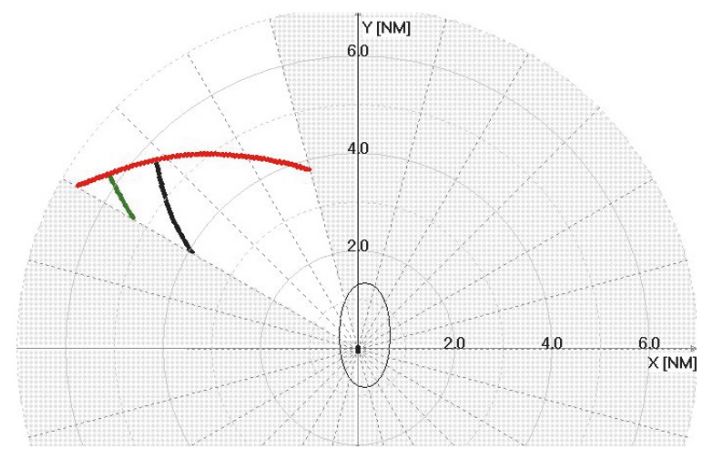

FIgURE 23: Action lines for stand-on crossing encounter with a target, whose true speed is 18 knots. Assumed are turns of $15^{\circ}$ to starboard without speed reduction (red) or with speed reduced by 6 knots (green), and 9 knots (black).

found that speed reductions do not bring significant progress for targets on closer relative bearings (Figures 23 and 24), especially for fast targets (Figure 24).

5.3. The Impact of Stability-Related Phenomena. In heavy weather conditions, the risk of stability-related phenomena

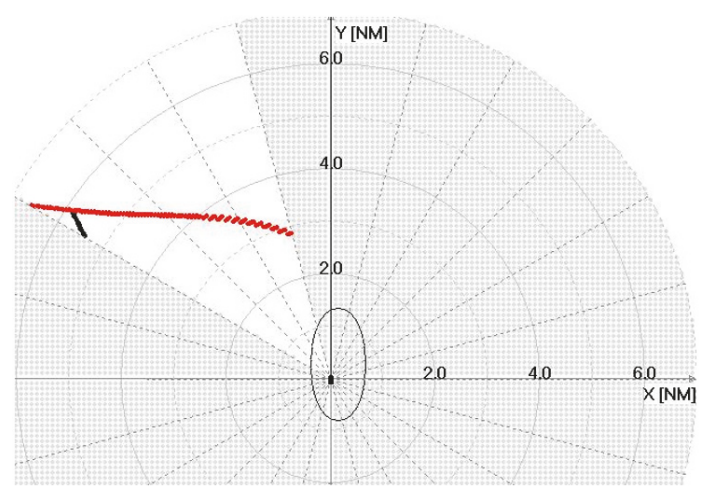

FIgURE 24: Action lines for stand-on crossing encounter with a target, whose true speed is 18 knots. Assumed are turns of $30^{\circ}$ to starboard without speed reduction (red) by 9 knots (the progress is marked in black).

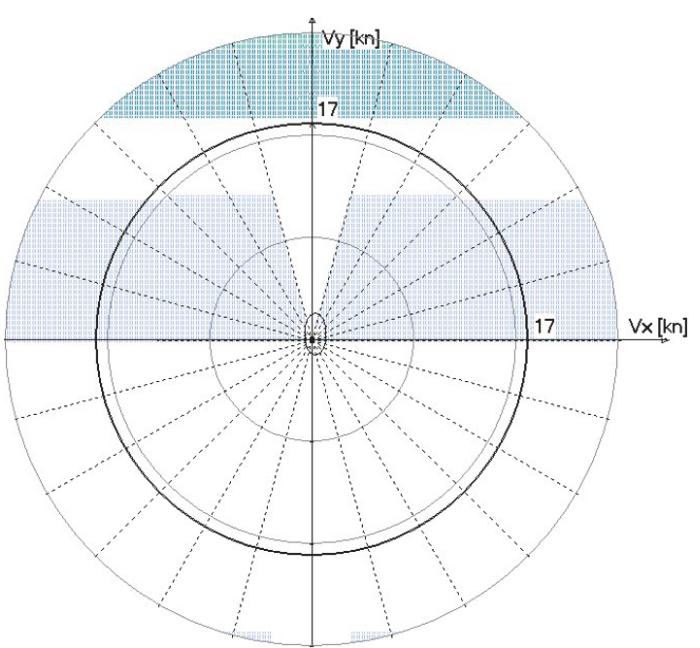

FIGURE 25: Sectors of own course and speed eliminated by risk of resonance (light blue) for wind of $20[\mathrm{~m} / \mathrm{s}]$ and wave from $180^{\circ}$.

may seriously affect the choice of manoeuvres. In particular, for the fixed own speed, not all own courses may be safe - some should be avoided. For all of the examples in this section, we assume that the target's true speed is 18 knots and the planned turns of the own ship are up to $90^{\circ}$. Speed reduction manoeuvres are not taken into account. However, because of weather conditions, the available course alterations are significantly smaller than assumed $90^{\circ}$. Each example includes a figure showing how exactly weather conditions limit possible manoeuvres. This is followed by a figure presenting action lines changing with the wave direction. The results cover all relative bearings of a target, though only bearings from about $112.5^{\circ}$ to $345^{\circ}$ are of interest for stand-on situations.

In Figure 25 the available own manoeuvres are limited to about $50^{\circ}$ to either side for a wind of $20[\mathrm{~m} / \mathrm{s}]$ and wave from $180^{\circ}$ because of resonance risk (light blue area). As a result, own manoeuvres should be started at a much larger distance (red line in Figure 26) for targets approaching from relative bearings of about $60^{\circ}$ to $75^{\circ}$ on port. Neutral wave direction 


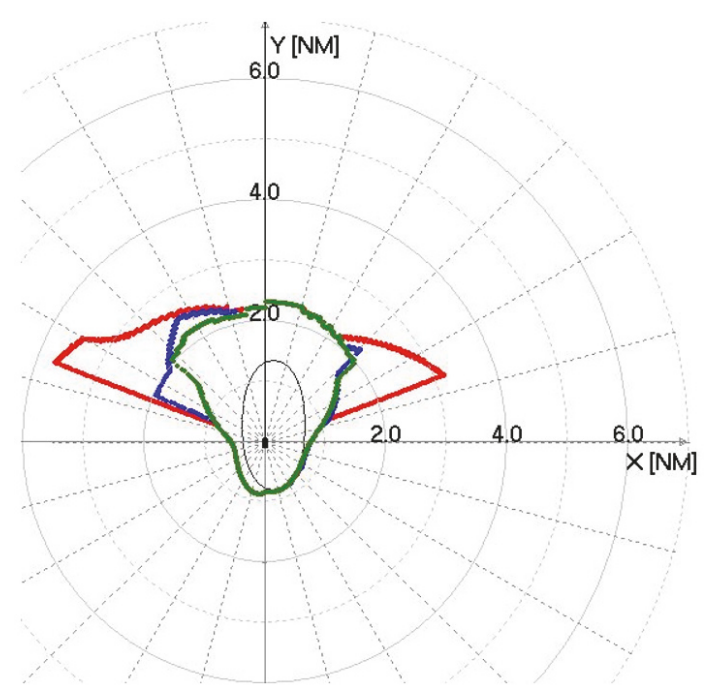

FIGURE 26: Action lines for stand-on encounter with a target, whose true speed is 18 knots. Manoeuvres to both sides are considered, but they are limited by risk of resonance. Wind of $20[\mathrm{~m} / \mathrm{s}]$ and wave from $0^{\circ}$ (green), $185^{\circ}$ (blue), and $180^{\circ}$ (red) are assumed.

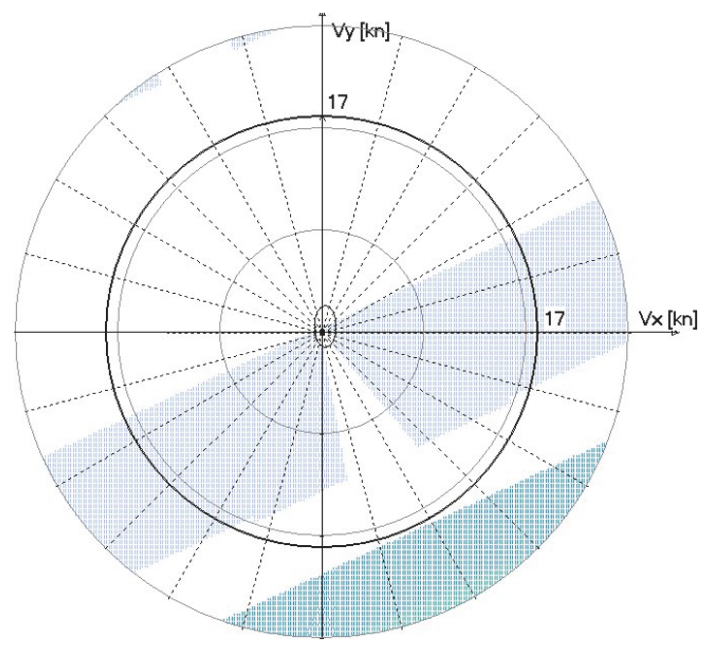

FIGURE 27: Sectors of own course and speed eliminated by risk of resonance (light blue) for wind of $20[\mathrm{~m} / \mathrm{s}]$ and wave from $335^{\circ}$.

(resulting in green action line) or moderately inconvenient wave direction (resulting in blue action line) allows for a manoeuvre performed later.

For the next example, it is additionally assumed that turns to starboard only are taken into account. In Figure 27, those turns are limited to about $65^{\circ}$ to the right for a wind of 20 $[\mathrm{m} / \mathrm{s}]$ and wave from $335^{\circ}$. Consequently, own manoeuvre must be initiated at a distance of about 3-3.5 nautical mile (red line in Figure 28) for targets approaching from relative bearings of about $60^{\circ}$ on port. Much smaller distances are needed for neutral wave direction (green action line) or moderate one (blue action line).

In Figure 29, the risk of successive high wave attack (turquoise area) limits possible turns to about $50^{\circ}$ to starboard

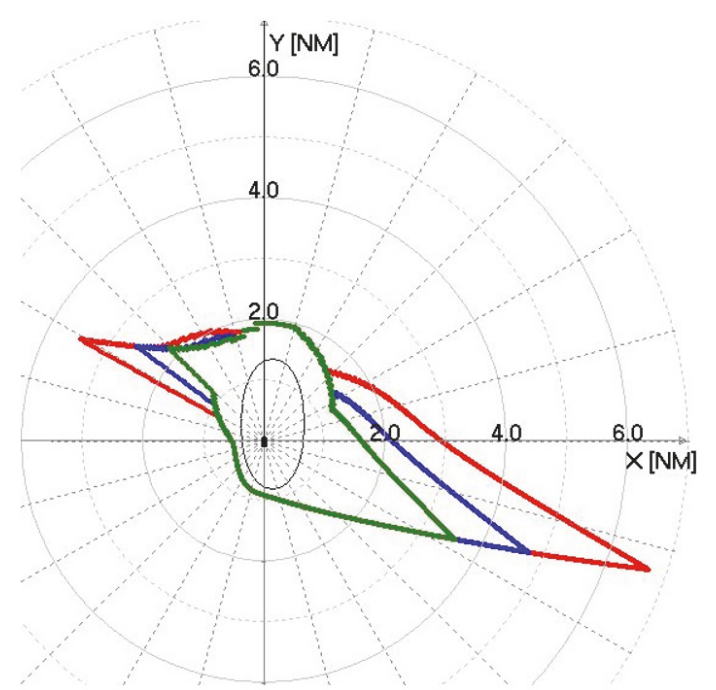

FIgURE 28: Action lines for stand-on encounter with a target, whose true speed is 18 knots. Manoeuvres to starboard only are considered and they are additionally limited by risk of resonance. Wind of 20 $[\mathrm{m} / \mathrm{s}]$ and wave from $10^{\circ}$ (green), $350^{\circ}$ (blue), and $335^{\circ}$ (red) are assumed.

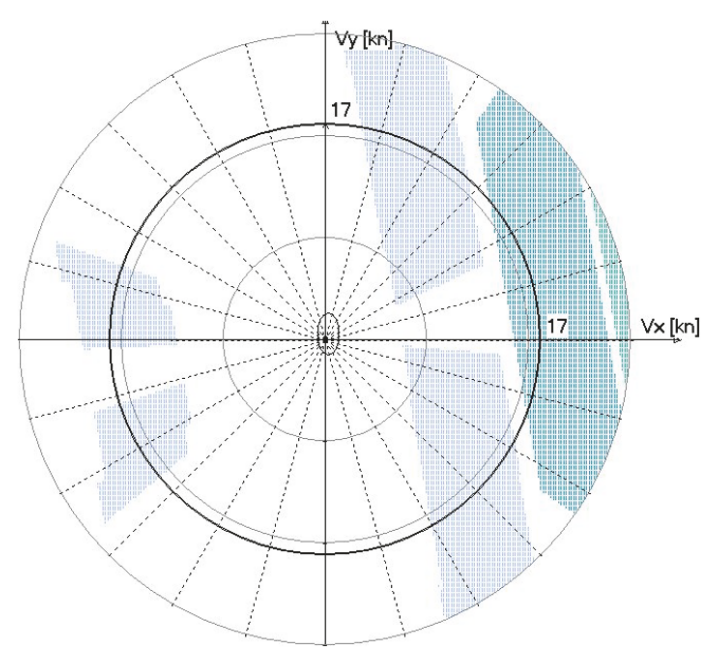

FIgURE 29: Sectors of own course and speed eliminated by risk of successive high wave attack (turquoise) and resonance (light blue) for wind of $17[\mathrm{~m} / \mathrm{s}]$ and wave from $260^{\circ}$.

for a wind of $17[\mathrm{~m} / \mathrm{s}]$ and wave from $260^{\circ}$. At the same time turns to port are limited to about $70^{\circ}$ by resonance risk (light blue area on port). Thus, own manoeuvre must be initiated at a distance of nearly 2.5 nautical mile for targets approaching from relative bearings of about $60^{\circ}-75^{\circ}$ (red line in Figure 30), when compared with about 1.5 nautical mile for neutral wave direction (blue action line).

In Figure 31, again the risk of successive high wave attack (turquoise area) limits possible turns to about $70^{\circ}$ to starboard for a wind of $17[\mathrm{~m} / \mathrm{s}]$ and wave from $280^{\circ}$. This leads to the necessity of starting own manoeuvre at a distance of about 4 nautical mile for targets on relative bearings of about $50^{\circ}-65^{\circ}$ on port (red line in Figure 32). The action distance is only 2 


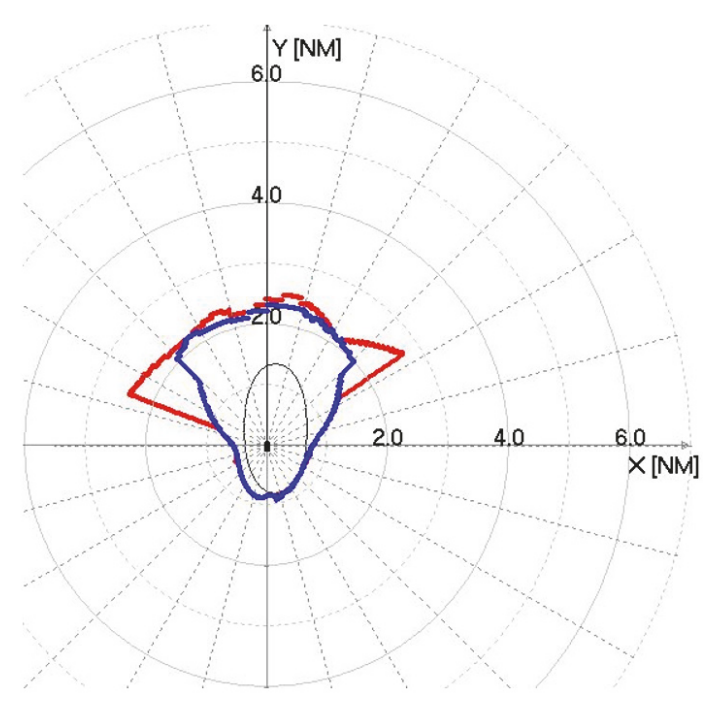

FIGURE 30: Action lines for stand-on encounter with a target, whose true speed is 18 knots. Manoeuvres to both sides are considered, but they are limited by risk of successive high wave attack and resonance. Wind of $17[\mathrm{~m} / \mathrm{s}]$ and wave from $0^{\circ}$ (blue) and $260^{\circ}$ (red) are assumed.

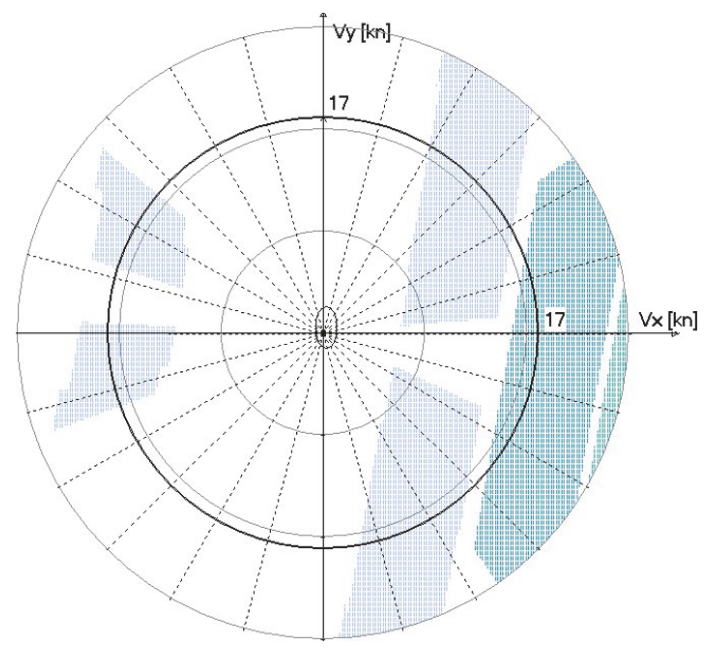

FIGURE 31: Sectors of own course and speed eliminated by risk of successive high wave attack (turquoise) and resonance (light blue) for wind of $17[\mathrm{~m} / \mathrm{s}]$ and wave from $280^{\circ}$.

nautical miles for neutral wave direction (blue action line in Figure 32).

\section{Discussion and Summary of Results}

The assumed ship is very manoeuvrable: course alterations of up to 180 degrees to either side can be performed within 2 minutes. To make the simulation results more universal and representative, test scenarios have been deliberately chosen to neutralize own ship's manoeuvrability by the high speeds of the targets (18 and 23 knots).

6.1. Being Overtaken. As mentioned before, when the own ship is the stand-on ship, the target is supposed to manoeuvre.

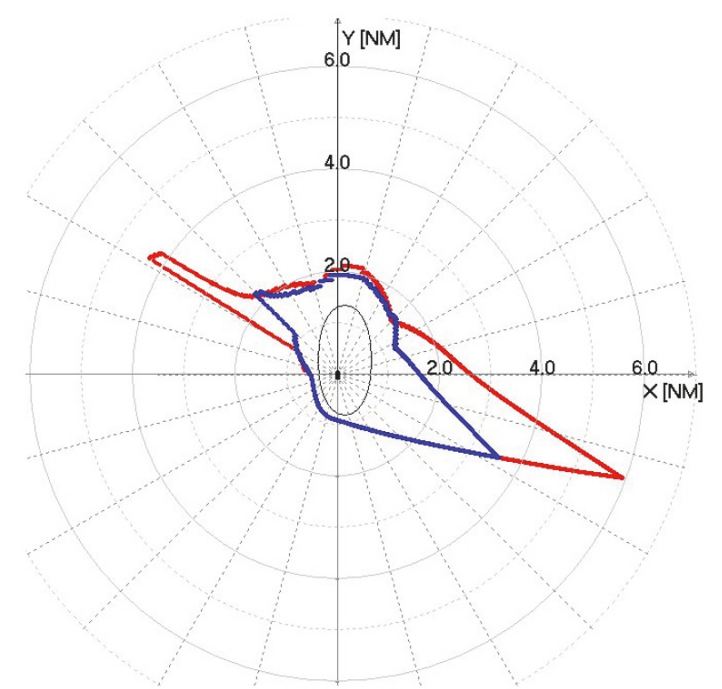

FIGURE 32: Action lines for stand-on encounter with a target, whose true speed is 18 knots. Manoeuvres to starboard only are considered and they are additionally limited by risk of successive high wave attack and resonance. Wind of $17[\mathrm{~m} / \mathrm{s}]$ and wave from $0^{\circ}$ (blue) and $280^{\circ}$ (red) are assumed.

Any evasive actions of the own ship are the last resort so they will be considered later than usual. In case of being overtaken evasive manoeuvres may be performed to either starboard or port. As has been evidenced in Figures 13 and 14, late evasive actions (at a distance of 1.2-1.5 NM) can still make it possible to avoid domain violations, as long as an appropriate, significant turn is made: 30 to $60^{\circ}$ away from the target. A combination of a smaller manoeuvre $\left(15^{\circ}\right)$ and a minor speed reduction may also suffice, but only for slightly larger distances of about $2 \mathrm{NM}$. Unfortunately, the situation of the own ship is much harder if a turn away from the target is impossible and a turn towards target has to be made instead. It is particularly difficult to avoid a target approaching from about $30^{\circ}$ behind the traverse. For a late action (at a distance of about $2 \mathrm{NM}$ ), a turn of $150^{\circ}$ has to be made then (Figure 15) or a combination of a smaller turn and a significant speed reduction (Figure 16). The former of the two manoeuvres is more effective and therefore preferred.

6.2. Stand-On Crossing. If the own ship is a stand-on vessel involved in a crossing encounter with a target on port, which does not give way, a turn to starboard should be made. A turn to starboard by $60^{\circ}$ to $90^{\circ}$ has been found sufficient at a distance of about $2 \mathrm{NM}$ (Figure 17) for a target of similar speed. Speed reduction is not necessary then, though a smaller turn will still be safe if the speed is reduced (Figure 18). As expected, a much larger action distance or course alteration is needed for a faster target (Figure 19) and unfortunately speed reduction does not help much then (Figure 20). This is especially true for targets on relative bearings between $45^{\circ}$ and $75^{\circ}$ on starboard. Smaller turns or smaller action distances are sufficient when the target's relative bearing is up to $45^{\circ}$ on starboard (Figure 21), though they can still be significant for fast targets (Figure 22) and 
speed reduction is nearly useless in some cases (Figures 23 and 24). The abovementioned facts of particularly large action distances for manoeuvres to one side only or for some relative bearings have not been investigated in research projects on ship arena shapes [36, 37] or action zone [24]. As evidenced here, the action distances can vary greatly even for the same type of an encounter and similar motion parameters of both ships.

6.3. The Impact of Stability-Related Phenomena. For the chosen ship model, resonance has been identified as the factor which limits own manoeuvres to the largest degree in heavy weather. In some unfortunate cases it can affect the possibility of manoeuvres to both starboard and port (Figures 25, 29, and 31 ). As a result, the own ship may have to choose turns smaller than desired ones and-consequently-may have to start them at a distance about twice larger, when compared to good weather conditions (Figures 26 and 28). As for successive high wave attack, it covers smaller range of own courses (Figures 29 and 31), but unfortunately this phenomena can appear for the same wind speeds as resonance (e.g., $17 \mathrm{~m} / \mathrm{s}$ ) and the combined effect of the two is a significant limiting factor. This is evident especially when manoeuvres to one side only are taken into account (Figure 32); own ship may then have to act at a distance of about 4 nautical miles, which is much more than expected for stand-on situations. The last of the researched phenomena- surf-riding and broaching-to-has only been found to appear for own speeds larger than 20 knots. Therefore, for the assumed own ship model it does not carry a direct risk and does not affect determined action distances, though it should certainly be taken into account when planning the increase of own speed. And-obviously - the effect of the above-mentioned issues may differ significantly for ship models other than the one chosen here.

\section{Summary and Conclusions}

The paper presents a method of determining action distances in stand-on situations, where the own ship does not normally manoeuvre, but may be forced to do so by the lack of appropriate action from the give-way ship. A ship domain and related parameters are used as criteria for detecting potential close quarters' situations. Own ship's dynamics are taken into account and based on that, own ship's movement is simulated. The method also takes into consideration stability-related phenomena, which may significantly limit own manoeuvres in heavy weather, translating to larger action distances (if only small turns are possible, they have to be done earlier). In general, the method achieves a high accuracy while keeping a low computational complexity, allowing for its applications on board of a ship and using in real time.

The method has been used in a series of simulations to determine action lines around the assumed own ship. Chosen scenarios cover various types of ship encounters, considered manoeuvres, and good or heavy weather conditions. It has been shown that action lines around the own ship can include some irregularities not mentioned in related past publications. Both above-mentioned observations are particularly true and noteworthy for heavy weather conditions, when the risk of resonance and successive high wave attack can limit possible manoeuvres to such a degree that manoeuvres have to be started at distances twice larger than normally. It must be emphasized, though, that presented simulation results are dependent on the behaviour of the ship that has been used in this research. Therefore, considerably different values of action distances may be obtained for other ship models, though some general tendencies outlined here are expected to be confirmed.

\section{Data Availability}

The data used to support the findings of this study are available from the corresponding author upon request.

\section{Conflicts of Interest}

The authors declare that they have no conflicts of interest.

\section{Acknowledgments}

The authors would like to thank Professor Jerzy Matusiak for making the LaiDyn code available and to Dr. Tomasz Hinz for performing numerical simulations of a ship motion.

\section{References}

[1] Y. Fujii and K. Tanaka, “Traffic Capacity," Journal of Navigation, vol. 24, no. 4, pp. 543-552, 1971.

[2] E. M. Goodwin, "A Statistical Study of Ship Domains," Journal of Navigation, vol. 28, no. 3, pp. 328-344, 1975.

[3] T. G. Coldwell, "Marine Traffic Behaviour in Restricted Waters," Journal of Navigation, vol. 36, no. 3, pp. 430-444, 1983.

[4] Z. Xu, J. Mou, and Y. Ji, "A Study of 3D Model of Ship Domain for Inland Waterway," Journal of Wuhan University of Technology (Transportation Science \& Engineering), vol. 3, pp. 380-383, 2004.

[5] N. Wang, "An intelligent spatial collision risk based on the quaternion ship domain," Journal of Navigation, vol. 63, no. 4, pp. 733-749, 2010.

[6] Z. Pietrzykowski, "Ship's Fuzzy Domain - a Criterion for Navigational Safety in Narrow Fairways," Journal of Navigation, vol. 61 , no. $03,2008$.

[7] Z. Pietrzykowski and J. Uriasz, "The ship domain - A criterion of navigational safety assessment in an open sea area," Journal of Navigation, vol. 62, no. 1, pp. 93-108, 2009.

[8] M. G. Hansen, T. K. Jensen, T. Lehn-Schioler, K. Melchild, F. M. Rasmussen, and F. Ennemark, "Empirical ship domain based on AIS data," Journal of Navigation, vol. 66, no. 6, pp. 931-940, 2013.

[9] Y. Wang and H.-C. Chin, "An Empirically-Calibrated Ship Domain as a Safety Criterion for Navigation in Confined Waters," Journal of Navigation, vol. 69, no. 2, pp. 257-276, 2015.

[10] R. Szlapczynski and J. Szlapczynska, "Review of ship safety domains: Models and applications," Ocean Engineering, vol. 145, pp. 277-289, 2017.

[11] R. Szlapczynski, "A new method of planning collision avoidance manoeuvres for multi-target encounter situations," The Journal of Navigation, vol. 61, no. 2, pp. 307-321, 2008. 
[12] A. Lazarowska, "A new deterministic approach in a decision support system for ship'," Expert Systems with Applications, pp. 1-10, 2016.

[13] J. Liu, F. Zhou, Z. Li, M. Wang, and R. W. Liu, "Dynamic Ship Domain Models for Capacity Analysis of Restricted Water Channels," Journal of Navigation, vol. 69, no. 03, pp. 481-503, 2015.

[14] E. van Iperen, "Classifying Ship Encounters to Monitor Traffic Safety on the North Sea from AIS Data," TransNav, the International Journal on Marine Navigation and Safety of Sea Transportation, vol. 9, no. 1, pp. 51-58, 2015.

[15] X. Wu, A. L. Mehta, V. A. Zaloom, and B. N. Craig, "Analysis of waterway transportation in Southeast Texas waterway based on AIS data," Ocean Engineering, vol. 121, pp. 196-209, 2016.

[16] W. Zhang, F. Goerlandt, P. Kujala, and Y. Wang, "An advanced method for detecting possible near miss ship collisions from AIS data," Ocean Engineering, vol. 124, pp. 141-156, 2016.

[17] F. Van Westrenen and J. Ellerbroek, "The Effect of Traffic Complexity on the Development of Near Misses on the North Sea," IEEE Transactions on Systems, Man, and Cybernetics: Systems, vol. 47, no. 3, pp. 432-440, 2017.

[18] F. Goerlandt and P. Kujala, "On the reliability and validity of ship-ship collision risk analysis in light of different perspectives on risk," Safety Science, vol. 62, pp. 348-365, 2014.

[19] F. Goerlandt and J. Montewka, "Maritime transportation risk analysis: Review and analysis in light of some foundational issues," Reliability Engineering \& System Safety, vol. 138, pp. 115134, 2015.

[20] X. Qu, Q. Meng, and L. Suyi, "Ship collision risk assessment for the Singapore Strait," Accident Analysis \& Prevention, vol. 43, no. 6, pp. 2030-2036, 2011.

[21] J. Weng, Q. Meng, and X. Qu, "Vessel collision frequency estimation in the Singapore Strait," Journal of Navigation, vol. 65, no. 2, pp. 207-221, 2012.

[22] K. Benedict, M. Kirchhoff, S. Fischer, M. Gluch, S. Klaes, and M. Baldauf, "Application of Fast Time Simulation Technologies for enhanced Ship Manoeuvring Operation," IFAC Proceedings Volumes, vol. 43, no. 20, pp. 79-84, 2010.

[23] K. Benedict, S. Fischer, M. Gluch et al., "Innovative fast time simulation tools for briefing / debriefing in advanced ship handling simulator training and ship operation," Transactions on Maritime Science, vol. 6, no. 1, pp. 24-38, 2017.

[24] G. H. Dinh and N. Im, "The combination of analytical and statistical method to define polygonal ship domain and reflect human experiences in estimating dangerous area," International Journal of e-Navigation and Maritime Economy, vol. 4, pp. 97108, 2016.

[25] P. Krata and J. Montewka, "Assessment of a critical area for a give-way ship in a collision encounter," Archives of Transport, vol. 34, no. 2, pp. 51-60, 2015.

[26] P. Krata, J. Montewka, and T. Hinz, "Towards the Assessment of Critical Area in a Collision Encounter Accounting for Stability Conditions of a Ship," Pr. Nauk. Politech. Warsz. XX, p. 10, 2016.

[27] C. G. Soares and A. P. Teixeira, "Risk assessment in maritime transportation," Reliability Engineering \& System Safety, vol. 74, no. 3, pp. 299-309, 2001.

[28] J. Wang, "Maritime Risk Assessment and its Current Status," Quality and Reliability Engineering International, vol. 22, no. 1, pp. 3-19, 2006.

[29] J.-F. Balmat, F. Lafont, R. Maifret, and N. Pessel, "A decisionmaking system to maritime risk assessment," Ocean Engineering, vol. 38, no. 1, pp. 171-176, 2011.
[30] IMO, Resolution MSC/Circ.1023/MEPC/Circ.392. Guidelines for Formal Safety Assessment (FSA) for use in the IMO rule-making process, $2002 \mathrm{~b}$.

[31] S. Hu, Q. Fang, H. Xia, and Y. Xi, "Formal safety assessment based on relative risks model in ship navigation," Reliability Engineering \& System Safety, vol. 92, no. 3, pp. 369-377, 2007.

[32] J. Montewka, F. Goerlandt, and P. Kujala, "On a systematic perspective on risk for formal safety assessment (FSA)," Reliability Engineering \& System Safety, vol. 127, pp. 77-85, 2014.

[33] IMO, Resolution MSC-MEPC.2/Circ.12. Revised guidelines for Formal Safety Assessment (FSA) for use in the IMO rule-making process, 2015.

[34] S.-L. Kao, K.-T. Lee, K.-Y. Chang, and M.-D. Ko, "A fuzzy logic method for collision avoidance in vessel traffic service," Journal of Navigation, vol. 60, no. 1, pp. 17-31, 2007.

[35] M. Hänninen and P. Kujala, "Influences of variables on ship collision probability in a Bayesian belief network model," Reliability Engineering \& System Safety, vol. 102, pp. 27-40, 2012.

[36] P. V. Davis, M. J. Dove, and C. T. Stockel, "A Computer Simulation of Marine Traffic Using Domains and Arenas," Journal of Navigation, vol. 33, no. 2, pp. 215-222, 1980.

[37] B. A. Colley, R. G. Curtis, and C. T. Stockel, "Manoeuvring times, domains and arenas," Journal of Navigation, vol. 36, no. 2, pp. 324-328, 1983.

[38] H. Hilgert, "Defining the Close-Quarters Situation at Sea," Journal of Navigation, vol. 36, no. 3, pp. 454-461, 1983.

[39] IMO, Resolution MSC.137(76), Standards for ship manoeuvrability, 2002a.

[40] A. N. Cockcroft, N. Alfred, and J. N. F. Lameijer, A guide to the collision avoidance rules: international regulations for preventing collisions at sea, Elsevier, 2012.

[41] H. Hilgert and M. Baldauf, "A common risk model for the assessment of encounter situations on board ships," Deutsche Hydrographische Zeitschrift, vol. 49, no. 4, pp. 531-542, 1997.

[42] C. Denker, M. Baldauf, S. Fischer et al., "E-Navigation based cooperative collision avoidance at sea: The MTCAS approach," in Proceedings of the 24th European Navigation Conference, ENC 2016, Finland, June 2016.

[43] M. Baldauf, R. Mehdi, S. Fischer, and M. Gluch, "A perfect warning to avoid collisions at sea?" Scientific Journals of the Maritime University of Szczecin, vol. 49, pp. 53-64, 2017.

[44] J. Zhang, X. Yan, X. Chen, L. Sang, and D. Zhang, "A novel approach for assistance with anti-collision decision making based on the International Regulations for Preventing Collisions at Sea," Proceedings of the Institution of Mechanical Engineers, Part M: Journal of Engineering for the Maritime Environment, vol. 226, no. 3, pp. 250-259, 2012.

[45] PRS, Explanatory notes to the standards for ship manoeuvrability, Informative publication No 25/I, 2008.

[46] DNV-GL, "Guidelines for Sea Trials of Motor Vessels, Rules for Classification and Construction," Additional Rules and Guidelines, 2012.

[47] ITTC, Recommended Procedures and Guidelines: Full Scale Measurements Manoeuvrability, Full Scale Manoeuvring Trials, 2002.

[48] ABS, Guide for vessel maneuverability, 2006, Guide for vessel maneuverability.

[49] K. Benedict, M. Kirchhoff, M. Gluch, S. Fischer, and M. Baldauf, "Manoeuvring simulation on the bridge for predicting motion of real ships and as training tool in ship handling simulators," in 
Proceedings of the 8th International Navigational Symposium on Marine Navigation and Safety of Sea Transportation, Trans-Nav 2009, pp. 53-58, Poland, June 2009.

[50] J. Artyszuk, L. Gucma, and M. Gucma, "Manoeuvring Simulation Methods Applied to Determine the Shape and Operational Condition of New Ports - Mielno Port Case Study," Scientific Journals Maritime University of Szczecin, vol. 37, no. 109, pp. 1015, 2014.

[51] X. Wang, Z. Zou, and F. Xu, "Modeling of ship manoeuvring motion in 4 degrees of freedom based on support vector machines," in Proceedings of the ASME 32nd International Conference on Ocean, Offshore and Arctic Engineering, OMAE '13, France, June 2013.

[52] T. I. Fossen, "A nonlinear unified state-space model for ship maneuvering and control in a seaway," International Journal of Bifurcation and Chaos, vol. 15, no. 9, pp. 2717-2746, 2005.

[53] O. El Moctar, U. Lantermann, P. Mucha, J. Höpken, and T. E. Schellin, "RANS-based simulated ship maneuvering accounting for hull-propulsor-engine interaction," Ship Technology Research, vol. 61, no. 3, pp. 142-161, 2014.

[54] R. Szlapczynski and P. Krata, "Determining and visualizing safe motion parameters of a ship navigating in severe weather conditions," Ocean Engineering, vol. 158, pp. 263-274, 2018.

[55] R. Szlapczynski and J. Szlapczynska, "An analysis of domainbased ship collision risk parameters," Ocean Engineering, vol. 126, pp. 47-56, 2016.

[56] R. Szlapczynski and J. Szlapczynska, "A Target Information Display for Visualising Collision Avoidance Manoeuvres in Various Visibility Conditions," Journal of Navigation, vol. 68, no. 6, pp. 1041-1055, 2015.

[57] ITTC, "Final Report and Recommendations to the 24th ITTC, in Proceedings of the 24th International Towing Tank Conference, 2005.

[58] D. Spanos and M. Palmquist, "Benchmark Study on Numerical Simulation Methods for the Prediction of Parametric Roll of Ships in Waves," in Proceedings of the 10th International Conference on Stability of Ships and Ocean Vehicles, pp. 1-9, 2009.

[59] J. Matusiak, "Dynamics of a rigid ship," Appplied Mechanics, 2013.

[60] J. Matusiak and C. Stigler, "Ship motion in irregular waves during a turning circle manoeuvre," in In Proceedings of 19th International Conference on Hydrodynamics in Ship Design. 4th International Symposium on Ship Manoeuvring, Ilawa, Poland, 2012.

[61] P. Krata and J. Szlapczynska, "Ship weather routing optimization with dynamic constraints based on reliable synchronous roll prediction," Ocean Engineering, vol. 150, pp. 124-137, 2018. 


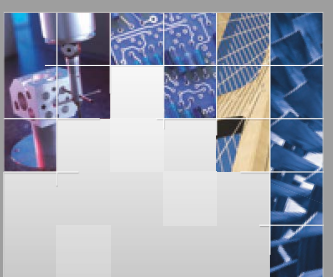

\section{Enfincering}
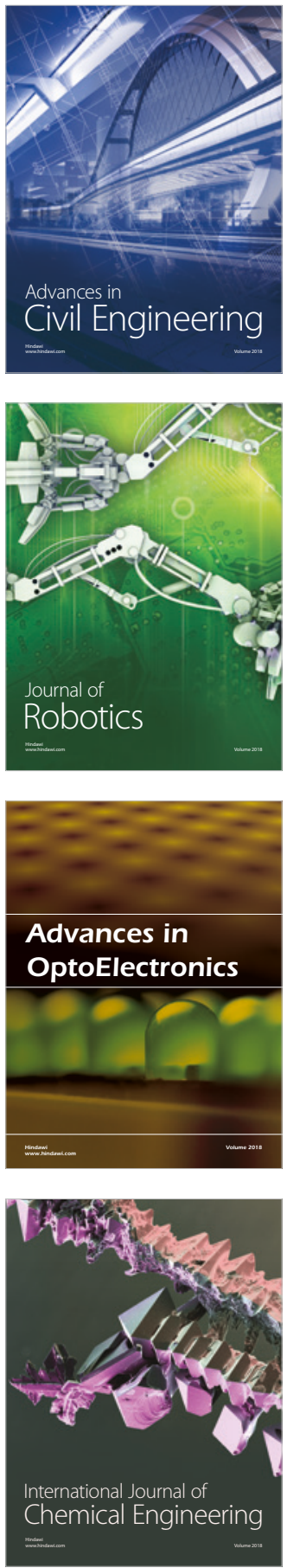

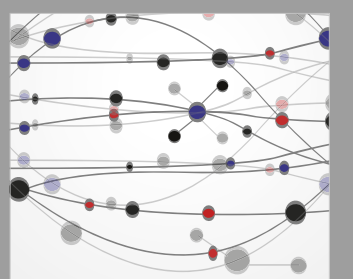

\section{Rotating \\ Machinery}

The Scientific World Journal

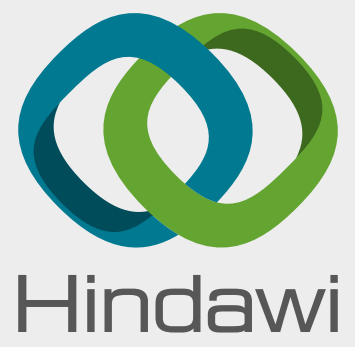

Submit your manuscripts at

www.hindawi.com
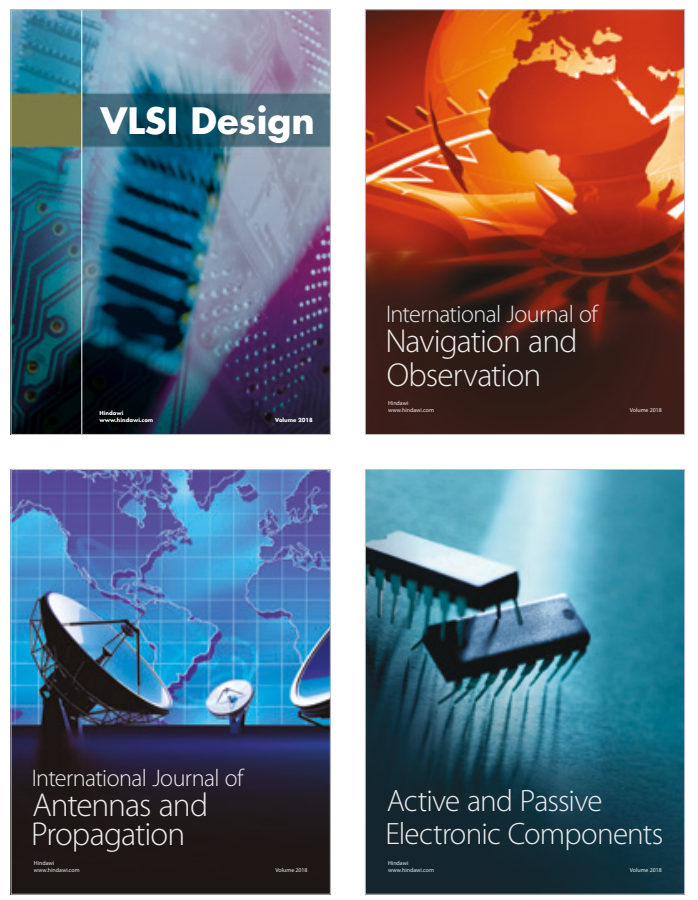
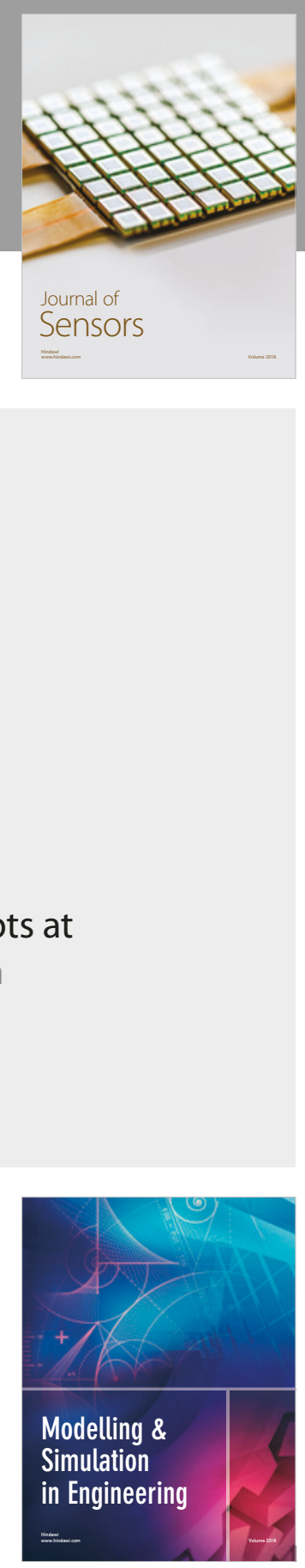

\section{Advances \\ Multimedia}
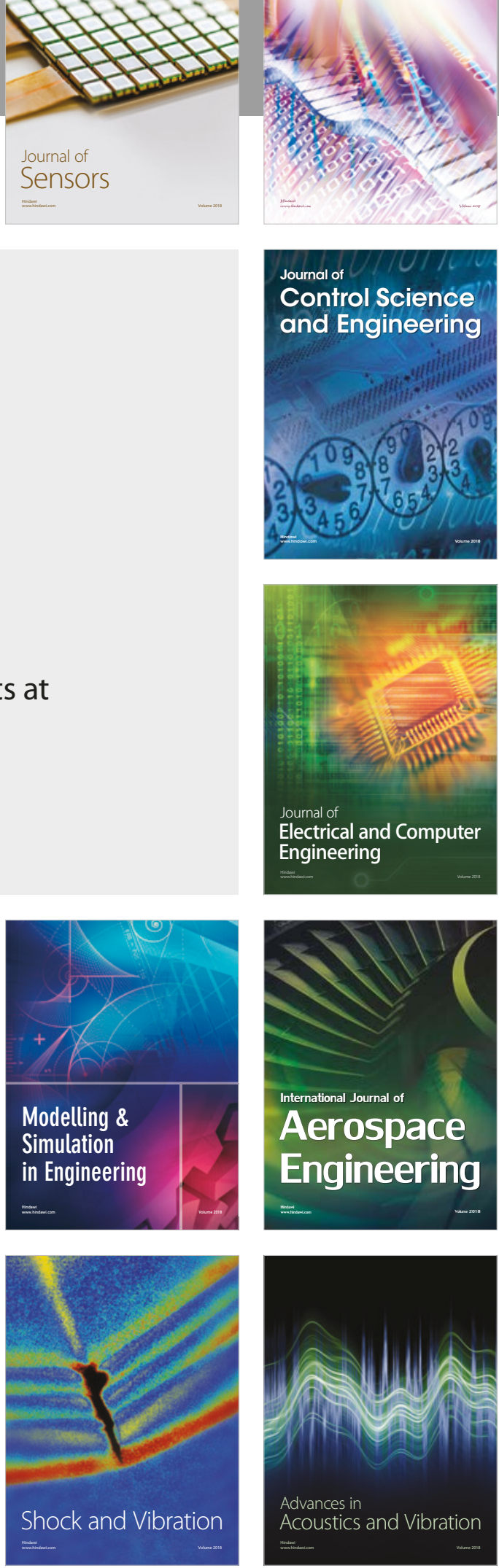